\title{
THE
}

1999

\section{A Numerical Investigation of the Local Ocean Response to Westerly Wind Burst Forcing in the Western Equatorial Pacific}

\author{
Raymond A. Richardson \\ University of Rhode Island \\ Isaac Ginis \\ University of Rhode Island, iginis@uri.edu \\ Lewis M. Rothstein \\ University of Rhode Island, Irothstein@uri.edu
}

Follow this and additional works at: https://digitalcommons.uri.edu/gsofacpubs

\section{Citation/Publisher Attribution}

Richardson, R. A., Ginis, I., \& Rothstein, L. M. (1999). A Numerical Investigation of the Local Ocean Response to Westerly Wind Burst Forcing in the Western Equatorial Pacific. J. Phys. Oceanogr., 29, 1334-1352. doi: 10.1175/1520-0485(1999)0292.0.C0;2.

Available at: https://doi.org/10.1175/1520-0485(1999)029<1334:ANIOTL>2.0.C0;2

This Article is brought to you for free and open access by the Graduate School of Oceanography at DigitalCommons@URI. It has been accepted for inclusion in Graduate School of Oceanography Faculty Publications by an authorized administrator of DigitalCommons@URI. For more information, please contact digitalcommons-group@uri.edu. 


\title{
A Numerical Investigation of the Local Ocean Response to Westerly Wind Burst Forcing in the Western Equatorial Pacific
}

\author{
RAYMOND A. RichaRdSON, IsAaC Ginis, AND LEWIS M. RothSTEIN \\ Graduate School of Oceanography, University of Rhode Island, Narragansett, Rhode Island
}

(Manuscript received 9 March 1998, in final form 18 September 1998)

\begin{abstract}
Numerical simulations of the local equatorial ocean response to idealized westerly wind burst (WWB) forcing are described. In particular, the authors examine the development and evolution of the subsurface westward jet (SSWJ) that has been observed to accompany these wind events. This westward current is interpreted as the signature of equatorial waves that accompany the downwelling and upwelling that occurs along the edges of the wind forcing region. Some important features of the SSWJ include maximum intensity toward the eastern edge of the forcing region, a time lag between the wind forcing and peak SSWJ development, and an eastward spreading of the SSWJ with time. The effect of wind burst zonal profile, magnitude, duration, and fetch on the SSWJ are explored. The response of an initially resting ocean to WWB forcing is compared with that for model oceans that are spun up with annual-mean surface fluxes and monthly varying fluxes. It is demonstrated that the gross features of the response for the spun up simulations can be well approximated by adding the background zonal current structure prior to the introduction of the wind burst to the initially resting ocean current response to the WWB. This result suggests that the zonal current structure that is present prior to the commencement of WWB forcing plays a key role in determining whether or not a SSWJ will develop.
\end{abstract}

\section{Introduction}

Easterly trade winds predominate over most of the equatorial Pacific, and the ocean response to these winds typically consists of a westward South Equatorial Current (SEC) and an eastward, subsurface Equatorial Undercurrent (EUC) in the immediate vicinity of the equator. In the western Pacific Ocean, the prevailing easterly trade winds are periodically interrupted by episodes of strong westerly wind, occurring typically in boreal winter and spring. These wind bursts have zonal extents that range from $10^{\circ}$ to $40^{\circ}$ of longitude, have maximum winds as high as $15 \mathrm{~m} \mathrm{~s}^{-1}$, and last anywhere from a couple of days to two weeks. In recent years, there has been considerable interest in these westerly wind bursts (WWBs) and their impact on both local and far-field ocean behavior. In the latter case, it has been suggested that eastward propagating Kelvin waves generated by WWBs can play a role in the warming of the eastern Pacific during El Niño events (Keen 1982; Harrison and Giese 1988).

Regarding the local response, it has long been recognized that strong westerly wind forcing on or near

Corresponding author address: Dr. Raymond A. Richardson, Graduate School of Oceanography, University of Rhode Island, Narragansett, RI 02822.

E-mail: rayr@auke.gso.uri.edu the equator leads to the development of an eastward surface Yoshida jet (Yoshida 1959). Less well understood has been the phenomenon, first observed by Hisard et al. (1970), that this surface response is often accompanied by a significant subsurface current directed to the west. Other observations of this subsurface westward jet (SSWJ), centered at depths in the 150-m range, were also reported by McPhaden et al. (1992), who presented current meter data from a Tropical Atmosphere Ocean Array buoy located at $0^{\circ}, 165^{\circ} \mathrm{E}$ and from ship transects in the region. Since that time, additional observations of the SSWJ have been made by many others (Delcroix et al. 1993a; Kuroda and McPhaden 1993). Most recently, observations during the TOGA COARE Intensive Observation Period experiment (1 November 1992-28 February 1993), an interval marked by several strong WWBs, also revealed significant westward flow between an eastward surface jet and the EUC (Delcroix et al. 1993b; Eldin et al. 1994; Delcroix and Eldin 1995; Smyth et al. 1996; Wijesekera et al. 1996).

Efforts to numerically simulate the ocean response to WWBs have focused primarily on the far-field behavior (Giese and Harrison 1990, 1991; Kindle and Phoebus 1995). Studies of the local response have been more limited. McPhaden et al. (1988) presented a one-dimensional, 11/2-layer model that reproduced the development of strong vertical velocity shear in response to WWB forcing, but the simplicity of that analysis did not allow consideration of the full three-dimensional 
aspects of the ocean response. Eriksen (1993) presented a numerical study of the ocean response to rapidly translating wind bursts and found that, for forcing of that type, the gravity wave response may dominate the current and internal displacement fields in the upper ocean. This is because other parts of the equatorial wave spectrum, such as Kelvin waves, cannot be excited by forcing fields whose rate of translation exceeds the wave propagation speeds. The Erikson analysis was based on a study by Nakazawa (1988), where it was suggested that WWBs were associated with disturbances in the tropospheric circulation know as Madden-Julian intraseasonal oscillations and translated eastward at speeds of approximately $10 \mathrm{~m} \mathrm{~s}^{-1}$. However, historical analyses of long-term data-assimilated atmospheric model products (Hartten 1996; Phoebus and Kindle 1994; Harrison and Vecchi 1997) have indicated that WWBs are often associated with developing tropical cyclones in one or both hemispheres and can be quite stationary in time, or even move slowly to the west as the storms associated with them move in that direction.

More recently Zhang and Rothstein (1998) have investigated the local ocean response to WWB forcing using a primitive equation model. In that work, it was shown that a short zonal wind fetch is conducive to the development of a SSWJ under the center of the forcing region on timescales of 10 days. However, that study was restricted to an investigation of the ocean response during the initial period in which the wind forcing was applied. The purpose of the present study is to explore the physics of the local dynamical response to nearstationary equatorial WWBs and, in particular, to elucidate the principal features of and the mechanism behind the SSWJ. This work is in many ways an extension of the work of Zhang and Rothstein (1998) to broader spatial and temporal regimes.

A series of experiments will be presented that investigate the local ocean dynamical response to WWB forcing and the manner in which that response changes when various aspects of the forcing field are altered. The rest of this paper is organized as follows: section 2 describes pertinant aspects of the model formulation, section 3 details the results of a series of experiments in which a range of parameters related to the wind field are varied in the context of an initially resting ocean, section 4 explores the influence of background current on the ocean response, and conclusions are presented in section 5 .

\section{Model description}

\section{a. Model physics}

For the experiments described in this study, we employ a nested-grid ocean general circulation model that provides high horizontal resolution in the forcing region while still allowing for the computation of a large-scale surrounding domain. This enables waves to propagate from the forcing region without the influence of domain boundaries and allows for high-resolution regional experiments to be conducted in the context of a basinscale circulating background current field. This hydrostatic, primitive equation model is described in detail in Ginis et al. (1998). The model employs the reducedgravity approximation, that is, only the upper ocean is actively simulated, with a motionless abyssal layer below. The vertical axis is partitioned according to a sigma coordinate in the manner of Gent and Cane (1989). Vertical mixing in the model occurs through a combination of several processes (Chen et al. 1994): a surface mixed layer undergoes mass exchange with the layer below according to a bulk turbulent kinetic energy balance (Kraus and Turner 1967), vertical mixing in the interior is determined by a Richardson number stability criterion, and finally, if necessary, the model is convectively adjusted to maintain hydrostatic stability. The momentum, heat, and continuity equations are solved and the prognostic variables of temperature, salinity, and velocity are calculated. The horizontal diffusion terms are calculated using the scales of motion resolved by the model and the local deformation field (Smagorinsky 1963). The density is calculated using the modified UNESCO equation of state (UNESCO 1981).

\section{b. Grid nesting}

The grid nesting procedure, motivated by the desire to more effectively resolve the local response to WWBs, involves a two-way interaction between adjacent meshes with the conservation properties of mass, momentum, and heat maintained across the grid interfaces (Ginis et al. 1998). In the experiments described below, one to two inner meshes are telescopically embedded in a coarser-resolution large-scale domain with inner grid resolutions two to three times finer then the surrounding grid, depending upon the particular experimental setup. In all of the experiments, the WWB forcing is applied within the finest resolution domain.

\section{c. Model geometry}

The experiments to be described fall into two general categories: resting ocean and circulating ocean. In the resting ocean experiments, a rectangular domain is used with boundaries at $10^{\circ} \mathrm{S}$ and $10^{\circ} \mathrm{N}$ in the meridional direction and at $130^{\circ} \mathrm{E}$ and $130^{\circ} \mathrm{W}$ in the zonal direction. Two grids are used for the resting ocean case, with the resolutions and grid locations indicated in Table 1.

The circulating ocean experiments are performed in a full tropical Pacific basin configuration where the coastline has been smoothed and islands eliminated. The model domain for these experiments is from $30^{\circ} \mathrm{S}$ to $30^{\circ} \mathrm{N}, 124^{\circ} \mathrm{E}$ to $70^{\circ} \mathrm{W}$. During the model spinup, a single grid was used with $1^{\circ}$ resolution in the zonal direction and variable resolution in the meridional direction that ranged from $13^{\circ}$ along the equator to as coarse as $2^{\circ}$ at the northern and southern boundaries. For the wind burst 
TABLE 1. Grid locations and resolutions for wind burst experiments.

\begin{tabular}{|c|c|c|c|c|c|}
\hline & \multicolumn{2}{|c|}{ Resting ocean experiments } & \multicolumn{3}{|c|}{ Circulating ocean experiments } \\
\hline & Grid 1 & Grid 2 & Grid 1 & Grid 2 & Grid 3 \\
\hline East-west extent & $130^{\circ} \mathrm{E}-130^{\circ} \mathrm{W}$ & $150^{\circ} \mathrm{E}-180^{\circ}$ & $124^{\circ} \mathrm{E}-70^{\circ} \mathrm{W}$ & $152^{\circ} \mathrm{E}-180^{\circ}$ & $158^{\circ} \mathrm{E}-175^{\circ} \mathrm{E}$ \\
\hline North-south extent & c $10^{\circ} \mathrm{S}-10^{\circ} \mathrm{N}$ & $5^{\circ} \mathrm{S}-5^{\circ} \mathrm{N}$ & $30^{\circ} \mathrm{S}-30^{\circ} \mathrm{N}$ & $10^{\circ} \mathrm{S}-10^{\circ} \mathrm{N}$ & $5^{\circ} \mathrm{S}-5^{\circ} \mathrm{N}$ \\
\hline Resolution & $2 / 3^{\circ}$ & $1 / 6^{\circ}$ & $1 / 2^{\circ}$ & $1 / 4^{\circ}$ & $1 / 8^{\circ}$ \\
\hline
\end{tabular}

experiments, the spinup model fields were interpolated onto a three-grid structure. The grid locations and resolutions for these experiments are also displayed in Table 1 .

The upper ocean is divided into 13 levels for all of the experiments presented here. This structure consists of a dynamically evolving surface mixed layer and a thermocline region. The initial mixed layer depth is set to $40 \mathrm{~m}$ for the resting ocean experiments and determined from climatology according to a density criterion for the circulating ocean experiments. The thermocline region is divided into the remaining 12 layers according to a prespecified ratio. The vertical resolution was $\sim 20$ $\mathrm{m}$ in the range $40-200 \mathrm{~m}$ (becoming as fine as $17 \mathrm{~m}$ under the deepest portions of the mixed layer during the wind burst experiments) and gradually coarser below.

\section{d. Model initialization and atmospheric forcing}

We will explore two scenarios for the circulating ocean experiments that vary according to the type of surface forcing applied during the model spinup. In the first case, annual-mean surface flux climatology is used (annual spinup), and in the second, monthly surface flux climatology is used (seasonal spinup). The model is initialized with annual mean Levitus (1982) temperature and salinity for the annual mean experiments and with January climatology for the seasonal case. The horizontal boundary conditions in the spinup runs are nonslip and nonflux at all boundaries. However, near the northern (southern) boundary of the domain, poleward

TABLE 2. Parameters for numerical experiments.

\begin{tabular}{|c|c|c|c|c|c|c|}
\hline Expt & $\begin{array}{c}\text { Max } \\
\text { wind } \\
\text { stress } \\
\left(\mathrm{N} \mathrm{m}^{-2}\right.\end{array}$ & $\begin{array}{c}\text { Dura- } \\
\text { tion } \\
\text { (days) }\end{array}$ & $\begin{array}{l}\text { Fetch } \\
(\text { deg) }\end{array}$ & Edge width & $\begin{array}{c}\text { Initial } \\
\text { ocean state }\end{array}$ & Lat \\
\hline 1 & 0.2 & 10 & 15 & Gaussian & Rest & $0^{\circ}$ \\
\hline 2 & 0.2 & 10 & 40 & $0^{\circ}$ & Rest & $0^{\circ}$ \\
\hline 3 & 0.05 & 10 & 20 & $8^{\circ}$ & Rest & $0^{\circ}$ \\
\hline 4 & 0.1 & 10 & 20 & $8^{\circ}$ & Rest & $0^{\circ}$ \\
\hline 5 & 0.2 & 10 & 20 & $8^{\circ}$ & Rest & $0^{\circ}$ \\
\hline 6 & 0.2 & 5 & 20 & $8^{\circ}$ & Rest & $0^{\circ}$ \\
\hline 7 & 0.2 & 15 & 20 & $8^{\circ}$ & Rest & $0^{\circ}$ \\
\hline 8 & 0.2 & 10 & 20 & $0^{\circ}$ & Rest & $0^{\circ}$ \\
\hline 9 & 0.2 & 10 & 10 & $0^{\circ}$ & Rest & $0^{\circ}$ \\
\hline 10 & 0.2 & 10 & 15 & Gaussian & Rest & $2^{\circ} \mathrm{S}$ \\
\hline 11 & 0.2 & 10 & 15 & Gaussian & Rest & $4^{\circ} \mathrm{S}$ \\
\hline 12 & 0.2 & 10 & 15 & Gaussian & Annual spinup & $0^{\circ}$ \\
\hline 13 & 0.2 & 10 & 15 & Gaussian & Seasonal spinup & $0^{\circ}$ \\
\hline
\end{tabular}

of $25^{\circ} \mathrm{N}(\mathrm{S})$, temperature and salinity are gradually relaxed toward climatology. The model starts from rest and is forced by either annual mean or seasonal (monthly) climatological surface wind stress and heat fluxes. The wind stress is derived from the Florida State University (FSU) pseudostress climatology (Goldenberg and O'Brien 1981). The heat flux $Q\left(\mathrm{SST}_{c}\right)$ is calculated using the simplified bulk formula of Seager et al. (1988), with annual-mean cloud cover from the International Satellite Cloud Climatology Project (Rossow and Schiffer 1991). We use the total cloud fraction to determine the heat flux, making no distinction between high, middle, and low clouds. This introduces some inaccuracies to the heat flux calculation and a small correction is applied to avoid excessive surface heating in some locations, most notably near the northern Central American coast. The Seager et al. algorithm also requires wind speed for the heat flux calculation. This speed was derived from the FSU wind stress assuming a surface drag coefficient of $1.5 \times 10^{-3}$. In the annual spinup experiment, the surface values of temperature and salinity were relaxed back to climatology on a timescale of 20 days for a mixed layer $30 \mathrm{~m}$ deep. This is necessary to avoid excessive model drift from climatology when forced with constant annual mean fluxes. No such relaxation term is required in the seasonal spinup. The model is integrated for three years for the annual spinup and for six years for the seasonal spinup. These integration lengths were sufficient to establish quasi equilibrium in the two scenarios, though any slow evolution of the background state should not strongly influence our conclusions about the local ocean response on the much shorter timescales of the wind burst experiments described in the following sections.

\section{Experimental results}

The following sections describe the results of a series of numerical experiments aimed at illuminating the basic properties of the SSWJ and the factors that affect its behavior and evolution. The various experimental settings are summarized in Table 2. The experiments can be broadly separated into those in which the model ocean was initially at rest and those in which an initial background circulation was present. Within the initially resting ocean category, the dependence of the ocean response on various parameters such as wind-stress zonal profile, wind duration and magnitude, and wind burst location are explored. In the circulating ocean experi- 
ments, the response of model oceans with two different background current configurations, the annual and seasonal spinups, is compared.

\section{a. Response of an initially resting ocean}

\section{1) An illustrative CASE}

To examine the principal features of the local zonal current response to WWB forcing, a stationary, idealized burst was applied along the equator with zonal wind stress $\tau_{0}^{\lambda}$ described by the following expression:

$$
\tau_{0}^{\lambda}=\tau_{\max }^{\lambda} e^{-\left(\lambda-\lambda_{0}\right)^{2} / L_{x}^{2}} e^{-\left(\phi-\phi_{0}\right)^{2} / L_{y}^{2}},
$$

where $\tau_{\max }=0.2 \mathrm{~N} \mathrm{~m}^{-2}, L_{x}=7.5^{\circ}$, and $L_{y}=3^{\circ}$. These spatial dimensions were chosen to be within the range of parameters observed historically (Harrison and Giese 1991). The burst was centered at $\phi_{0}=0^{\circ}, \lambda_{0}=165^{\circ} \mathrm{E}$ and was stationary in time. This wind stress was applied impulsively for 10 days and then turned off. The temperature and salinity stratification were taken from Levitus climatology for the location $0^{\circ}, 165^{\circ} \mathrm{E}$ and the mixed layer depth was chosen to be $40 \mathrm{~m}$. Changes in surface heat and freshwater flux associated with the wind burst are neglected in this and all the following experiments. Since our primary focus is on the dynamical response, we believe this is a reasonable simplification. This configuration will be referred to as experiment 1 .

Figure 1 shows zonal slices along the equator of the zonal velocity field every 5 days for the first 30 days after the initial imposition of the wind burst forcing Two features are immediately evident: a wind-driven eastward near-surface Yoshida jet and a westward SSWJ below. The surface jet accelerates for the duration of the wind forcing and decelerates thereafter. The SSWJ, on the other hand, does not reach its maximum until day 20 , ten days after the surface forcing has ceased. It undergoes a gradual eastward and downward spreading and, with the exception of the earliest times (day 5), shows a consistent eastward bias relative to the center of the wind burst forcing $\left(165^{\circ} \mathrm{E}\right)$. At later times, (days 25 and 30 ), the velocity structure becomes more complex and eastward flow below the SSWJ begins to develop, with some westward flow to the west of the wind burst center at SSWJ depths also becoming evident.

Before examining any of the effects of variations in wind forcing, some interpretation of the results of experiment 1 is required. Figure 2 shows the surface velocity field after 5 days of wind burst forcing. The zonal component can be seen to be convergent on the eastern side and divergent on the western side. The meridional velocity field is convergent all along the length of the forcing area, the result of the Coriolis force associated with the eastward wind stress. The total surface horizontal velocity field that results from these two components is strongly convergent on the eastern side of the forcing region and relatively weakly divergent on the western side. Continuity requires eastern side down- welling and western side upwelling, with the downwelling contribution dominating. Associated with this upwelling and downwelling will be deviations in the upper thermocline structure that will be seen to be directly associated with the subsurface current response, that is, the SSWJ.

To illustrate this point further, Fig. 3 shows zonal sections of temperature (variations of which are the principal source of density anomalies in this study) and pressure gradient force for experiment 1 . The eastern side downward deflection of the thermocline is readily apparent in the upper panels. This deviation has a negative pressure gradient force associated with it (lower panels) that is near the center of the forcing region at day 5 but is strongly biased toward the east by day 10 . The westward subsurface current development shown in Fig. 1 can be seen to closely correspond to the location of the negative pressure gradient force.

Figure 4 shows the vertical structure of the first four orthonormal baroclinic modes for the density profile used in experiment 1 . In the calculation of these modes, the reduced gravity system was approximated by setting the bottom layer thickness to be very large. The most important feature to note is that modes $2-4$ have significant westward amplitudes at depths of 120-200 m. Higher modes as well will have a westward peak just below the mixed layer. This indicates that baroclinic Kelvin waves of mode number greater than one that are associated with downward thermocline displacements on the eastern side of the forcing region will have a westward signature in the region just beneath the mixed layer. The actual amplitudes that the different vertical modes take in experiment 1 will also be affected by the relative strength with which they are forced. Since the meridional scale of the windburst in this experiment is somewhat larger than the first baroclinic radius of deformation, we can expect the projection coefficients onto the various modes to decrease with increasing mode number. We suggest that the SSWJ is primarily the signature of the total modal response associated with the thermocline deviations that arise along the edges of the wind forcing region.

The development of baroclinic Kelvin modes on the eastern side of the forcing region can be observed in the time series of Fig. 1. The first eastward propagating feature that emerges is the surface-concentrated eastward signal associated with the first Kelvin mode, which can be seen leaving the region of the plot on day 25 . Trailing that signal, the slower moving second mode becomes apparent, with an eastward surface flow and a westward flow below. As the second mode moves away from the forcing region, the third baroclinic mode, with an east-west-east zonal velocity structure as one moves down the water column, is visible in the day 25 and day 30 plots in the vicinity of $175^{\circ} \mathrm{E}$.

The development and eastward propagation of these baroclinic modes is further illustrated in Fig. 5. This figure shows time series of the zonal velocity on the 

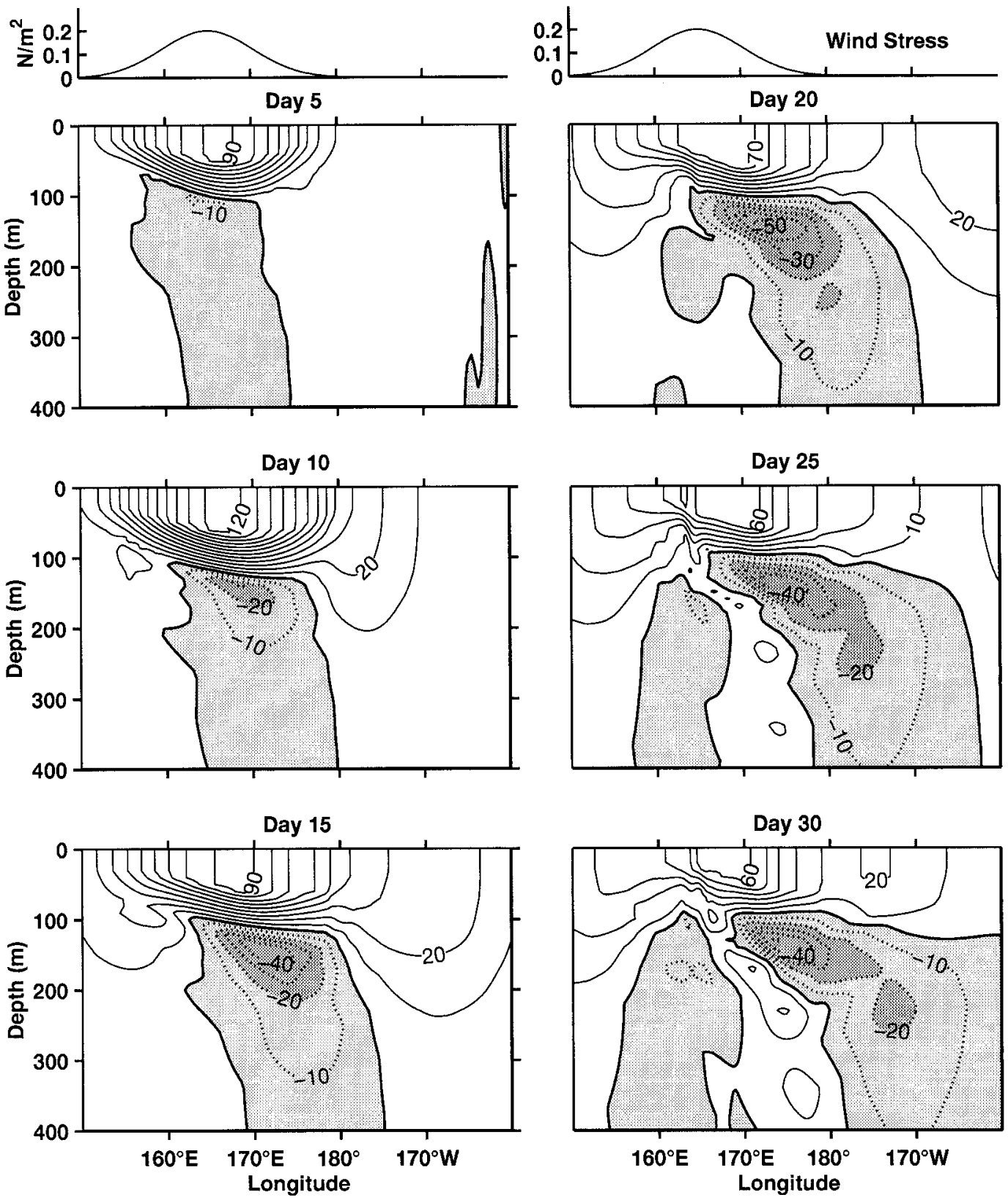

FIG. 1. Zonal sections along the equator of the zonal velocity $\left(\mathrm{cm} \mathrm{s}^{-1}\right)$ for expt 1 . Contour intervals are every $10 \mathrm{~cm}$ $\mathrm{s}^{-1}$. Regions of westward velocity are shaded and regions with westward velocities in excess of $20 \mathrm{~cm} \mathrm{~s}^{-1}$ are darkly shaded. Zonal wind stress profiles are included for reference.

equator at depths of 150 and $350 \mathrm{~m}$ at several different longitudes to the east of the center of the WWB. The left panels display the propagation of the (positive) first Kelvin mode pulse rapidly to the east followed by a long-lived change to westward flow as the second and higher baroclinic Kelvin modes propagate by the various longitudes. At this depth, the second mode response cannot be easily distinguished from the third mode, though a slight, eastward propagating kink in the plots may be indicative of the arrival of the third mode signal.
We argue that this blending of the westward signals of different modes in the $150-\mathrm{m}$ depth range is a primary component of the SSWJ feature. At the greater depth of $350 \mathrm{~m}$ (right panels) there is a difference in sign between the second and third modes. The arrival of the negative second mode signal, and the eventual sign reversal that indicates the passage of the third mode, is clearly visible at this depth. The close temporal correspondence between the change to positive velocities in the right panels and the kink in the negative velocity 


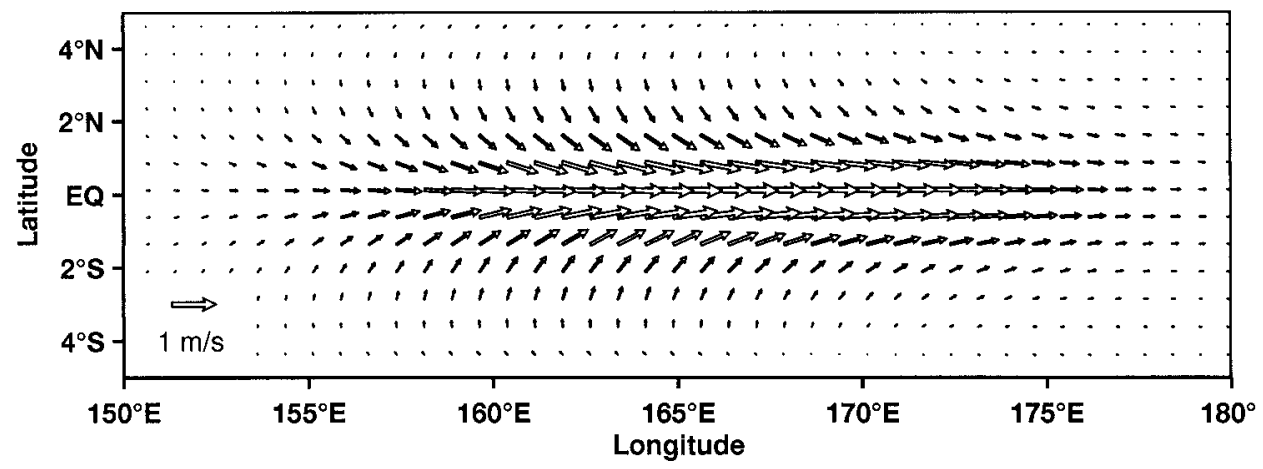

FIG. 2. Surface velocities after 5 days of WWB forcing for expt 1.

region of the left panels indicates that the aforementioned kink is, in fact, associated with the arrival of the third mode.

The first through third mode phase speeds can be derived from these plots. We derived phase speeds from the time difference between the velocity peaks at the $175^{\circ} \mathrm{E}$ and $175^{\circ} \mathrm{W}$ locations. These locations were chosen since, at longitudes farther east, the velocity peaks are broader and the uncertainty in the location of their centers is greater. The phase speeds for modes 1 through 3 are shown in Table 3, along with the results of the linear baroclinic mode calculation, used to derive the
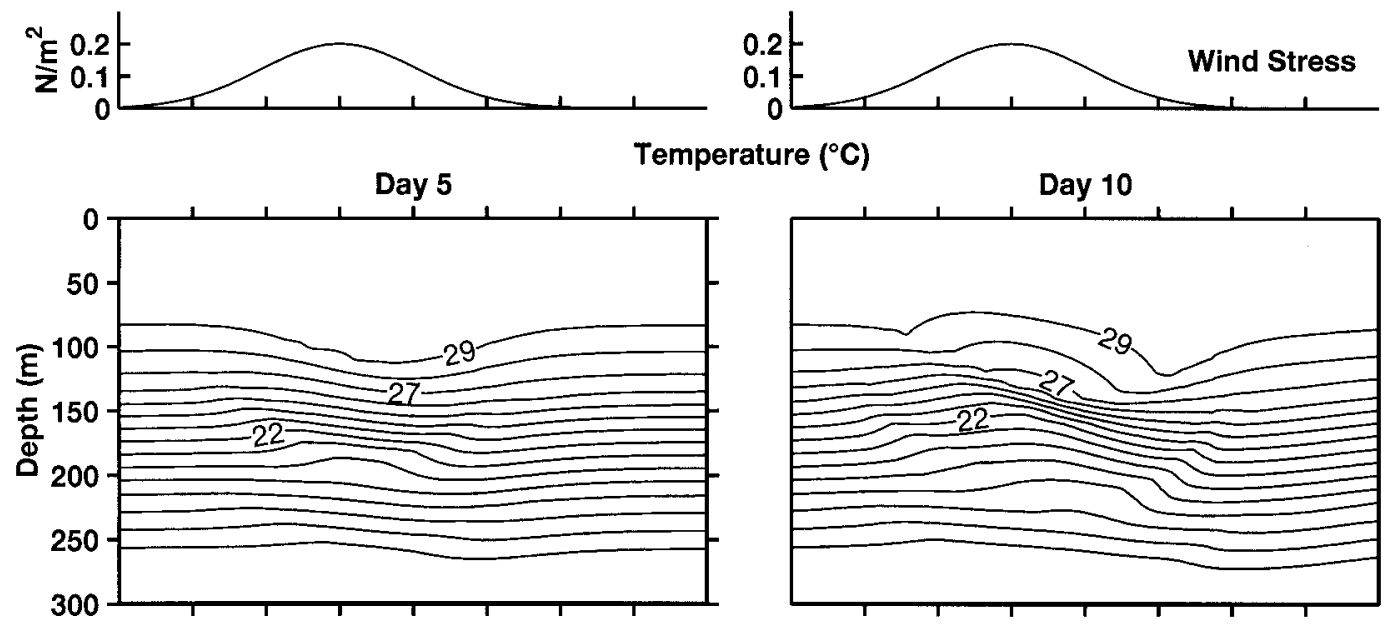

Day 10

Pressure Gradient Force $\left(\mathrm{m} / \mathrm{s}^{2} \times 10^{-7}\right)$
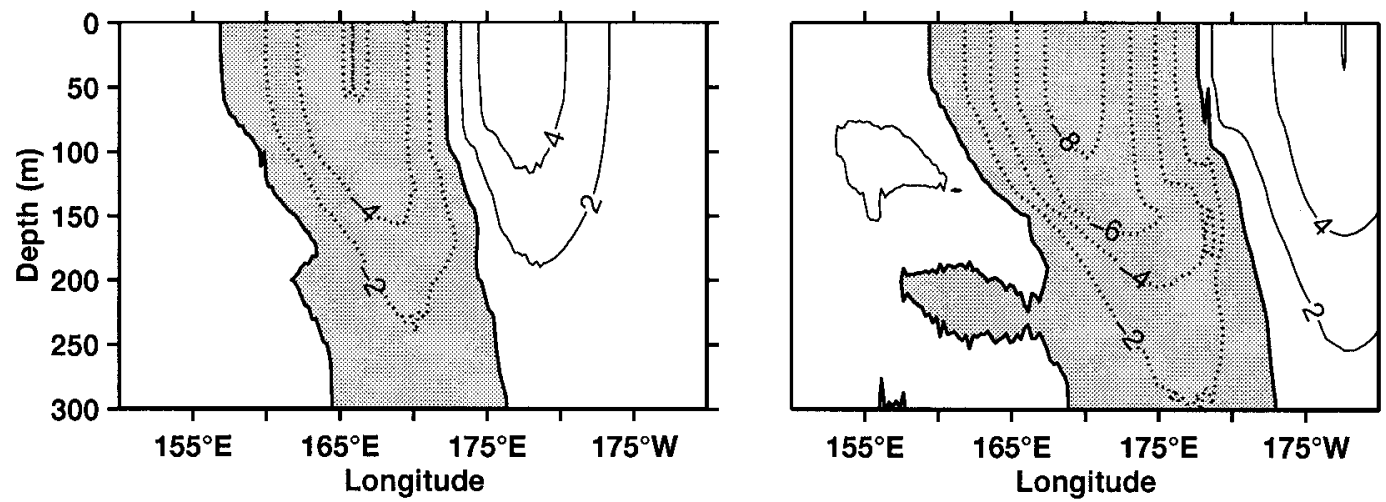

FIG. 3. Zonal sections along the equator of temperature and zonal pressure gradient force at days 5 and 10 for expt 1. The temperature contour interval is $1^{\circ} \mathrm{C}$ and the pressure gradient force contour interval is $2 \times 10^{-7} \mathrm{~m} \mathrm{~s}^{-2}$. Areas of westward pressure gradients are shaded. Zonal wind stress profiles are shown for reference. 


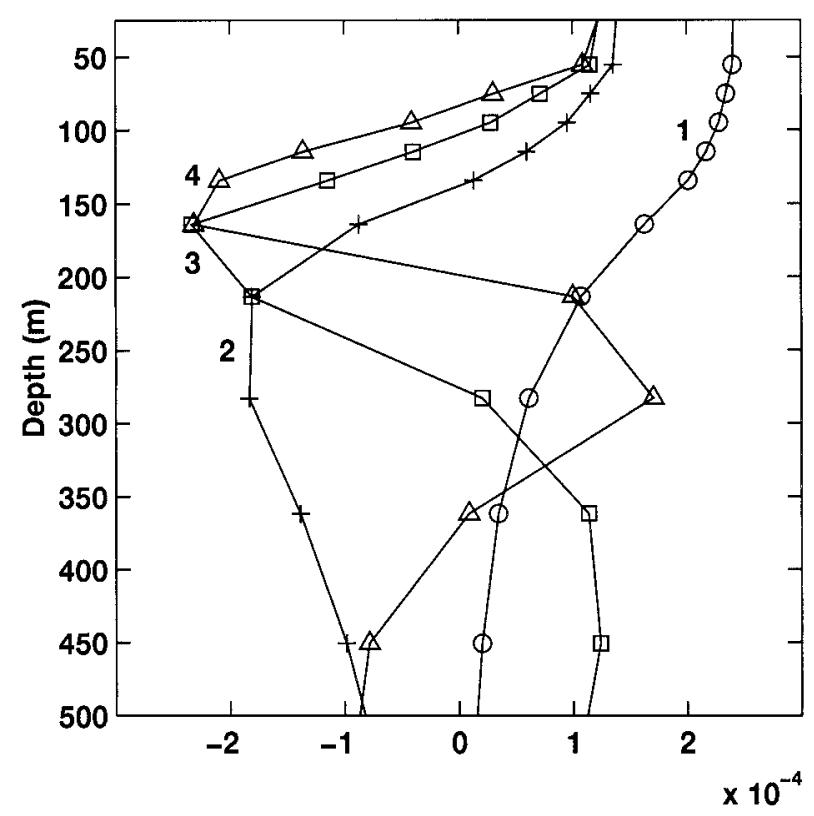

FIG. 4. Normalized vertical structure functions for the first four baroclinic modes corresponding to the density structure of expt 1 . Symbols indicate the location of model levels.
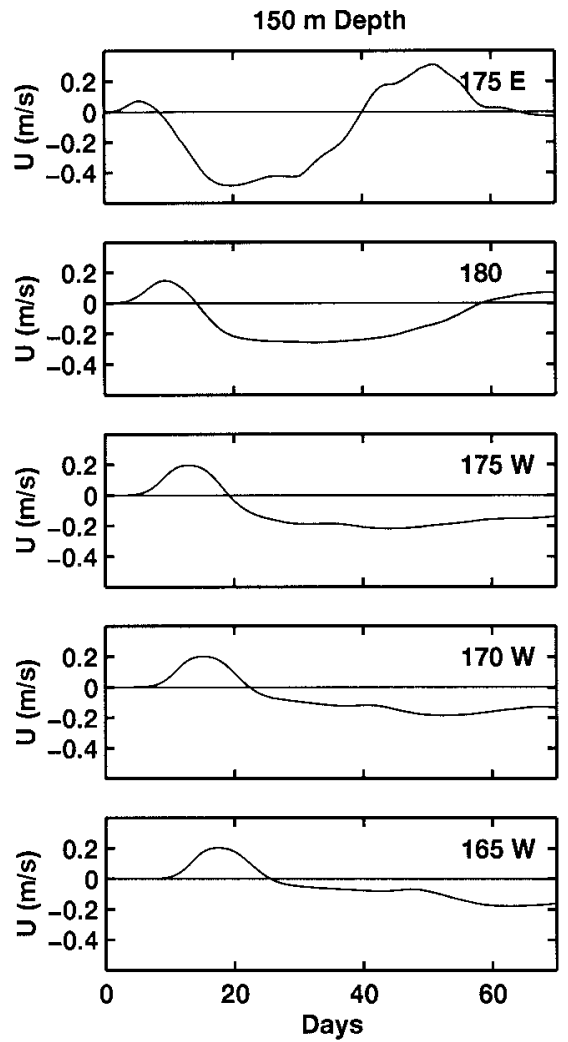

TABLE 3. Kelvin wave phase speeds for expt 1.

\begin{tabular}{cccc}
\hline \hline Mode & $\begin{array}{c}\text { Deformation } \\
\text { radius } \\
(\mathrm{km})\end{array}$ & $\begin{array}{c}\text { Phase speed- } \\
\text { analytical } \\
\left(\mathrm{m} \mathrm{s}^{-1}\right)\end{array}$ & $\begin{array}{c}\text { Phase speed- } \\
\text { model } \\
\left(\mathrm{m} \mathrm{s}^{-1}\right)\end{array}$ \\
\hline 1 & 247 & 2.80 & 2.99 \\
2 & 158 & 1.15 & 1.14 \\
3 & 125 & 0.72 & 0.78 \\
\hline
\end{tabular}

vertical structure functions displayed in Fig. 4. The model phase speeds agree with the analytical calculation within $10 \%$. This lends support to the baroclinic mode interpretation outlined above.

Associated with the generation and eastward propagation of the various baroclinic Kelvin waves at their respective velocities is an evolution of the region of subsurface westward flow. The SSWJ, which we will arbitrarily define to be the region encompassed by the $-20 \mathrm{~cm} \mathrm{~s}^{-1}$ zonal velocity contour, is characterized by several features enumerated above: an eastward bias relative to the wind burst center, a delayed maximum relative to the surface jet, and a gradual eastward and downward spreading. Each of these features can be interpreted within the context of the baroclinic mode description. The eastward bias is a reflection of the proposed forcing mechanism, pressure gradients associated with downwelling of the thermocline along the surface-
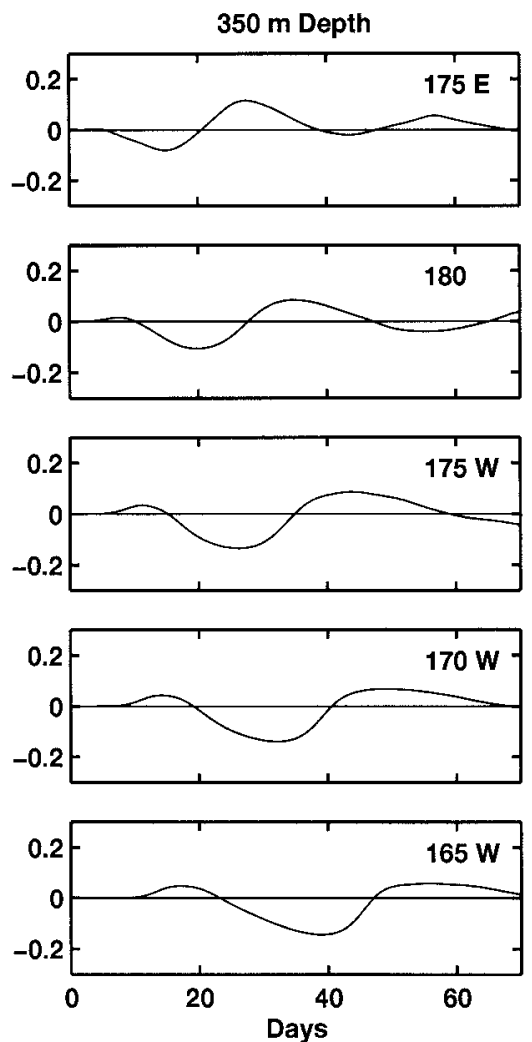

FIG. 5. Time series of the zonal velocity at 150 - and 350-m depths at various longitudes for expt 1 . 
convergent eastern side of the forcing region. The time lag in maximum current can be attributed to several factors. First, since the waves are being forced by the thermocline deviation (and the associated pressure gradient) rather than directly by the surface stress itself, they can continue to accelerate as long as the pressure gradient associated with this deviation has not been eliminated by the ocean adjustment process. Second, the first baroclinic Kelvin mode has a significant eastward amplitude at SSWJ depths (see Fig. 4) and therefore the SSWJ does not reach its maximum until the first mode pulse has moved away. This feature will be explored in more detail in some of the experiments to be described below. The last feature, the eastward spreading of the SSWJ, supports the hypothesis that the SSWJ comprises the superposition of several baroclinic modes that propagate with different eastward phase velocities, resulting in a broadening of the feature to the east over time.

This illustrative case has served to highlight some of the principal features of the local dynamical response to a WWB. Within this general qualitative framework, significant variations can take place that depend on the details of the wind stress spatial and temporal structure. Some of these variations will be examined in the following sections.

\section{2) SteP-Function ZONAL WIND PROFILE}

The selection of a smooth, Gaussian wind-stress profile in the above experiment was intended to reflect the sort of spatial wind variations that one might expect, at least in an aggregate sense, in real WWBs (Harrison and Vecchi 1997). It is instructive, however, to examine an even more idealized case, where the wind stress profile varies as a step function. The zonal variation in wind stress magnitude for this experiment, referred to as experiment 2 , is given by the following:

$$
\tau_{0}^{\lambda}= \begin{cases}\tau_{\max }, & \lambda_{1} \leq \lambda \leq \lambda_{2} \\ 0, & \lambda<\lambda_{1}, \lambda_{2}<\lambda .\end{cases}
$$

Here $\tau_{\max }$ is again $0.2 \mathrm{~N} \mathrm{~m}^{-2}$ and $\lambda_{1}$ and $\lambda_{2}$ are $145^{\circ} \mathrm{E}$ and $175^{\circ} \mathrm{W}$, respectively. The rather long $40^{\circ}$ zonal fetch, in conjunction with the step-function wind shape, will serve to isolate the contributions to the overall response from the different waves generated along the eastern and western edges. This will enable us to determine some of the individual wave processes that may have combined to form the broad response of experiment 1 .

The zonal velocity profiles along the equator are plotted in the same fashion as for experiment 1 in Fig. 6. One immediate difference from the smoother wind profile case of experiment 1 is that the western edge zonal velocity divergence is strong enough that the compensating effect of meridional convergence is relatively unimportant, and the resulting thermocline upwelling on the western side is comparable in magnitude to the eastern side downwelling. The consequence of this is that the western edge of the forcing region in experiment 2 is the site of significant wave activity of its own, a feature that was less significant in experiment 1 .

From the standpoint of SSWJ generation, Fig. 6 can be interpreted as follows. The upwelling and downwelling thermocline perturbations on the western and eastern edges, respectively, are accompanied by a spectrum of waves in both locales. An important feature to note, however, is that these spectra have opposite sign: that is, while the eastern edge first baroclinic mode Kelvin wave has an eastward zonal velocity signature (the "downwelling" Kelvin wave), the western edge first mode Kelvin wave (the "upwelling" wave) has westward velocities associated with it.

We have heretofore focused primarily on eastward moving Kelvin waves, but westward propagating Rossby waves will also be seen to play a role in experiment 2. Contrary to the Kelvin wave case, the first baroclinic Rossby mode on the upwelling western edge has an eastward velocity signature, while the eastern edge first baroclinic Rossby mode has westward velocities along the equator.

The day 5 plot in Fig. 6 shows the beginnings of the development of two westward subsurface velocity maxima on the edges of the forcing region, each of which is paired with a neighboring eastward maxima. The thermocline depression on the eastern edge produces an eastward acceleration on its eastern half and a westward acceleration on its western half. The domed isopycnals on the upwelling western edge of the forcing region do just the opposite. The first upwelling Kelvin mode, the westward surface velocity of which is masked by the Yoshida jet, is seen to emanate from the western edge and spread to the east with time. The initial signs of a westward propagating first Rossby mode with its eastward velocity signature can also be seen spreading from the western edge. At the eastern edge of the forcing region, the downwelling conditions are associated with a combination of higher order Kelvin modes as discussed in the context of experiment 1 and the easternside first Rossby mode. The eastern edge first Rossby mode, like the first Kelvin mode from the western edge, has its westward surface character masked by the Yoshida jet.

By day 10, the eastward propagation of the first Kelvin mode from the western edge and, to a lesser extent, the westward propagation of the first Rossby mode from the eastern edge have narrowed the gap between the two subsurface westward velocity maxima. The first Kelvin wave phase speed is $\sim 2.2^{\circ} \mathrm{day}^{-1}$ (see Table 3), which would put the leading edge of the western side first Kelvin pulse near $167^{\circ} \mathrm{E}$ by day 10 . The day 10 plot has an extra contour line at $-3 \mathrm{~cm} \mathrm{~s}^{-1}$ to illustrate this point. One can see that the leading edge of subsurface westward maximum emanating from the western edge of the forcing region, as judged by the position of this $-3 \mathrm{~cm} \mathrm{~s}^{-1}$ contour line, is in very close agreement with the $167^{\circ} \mathrm{E}$ prediction. 

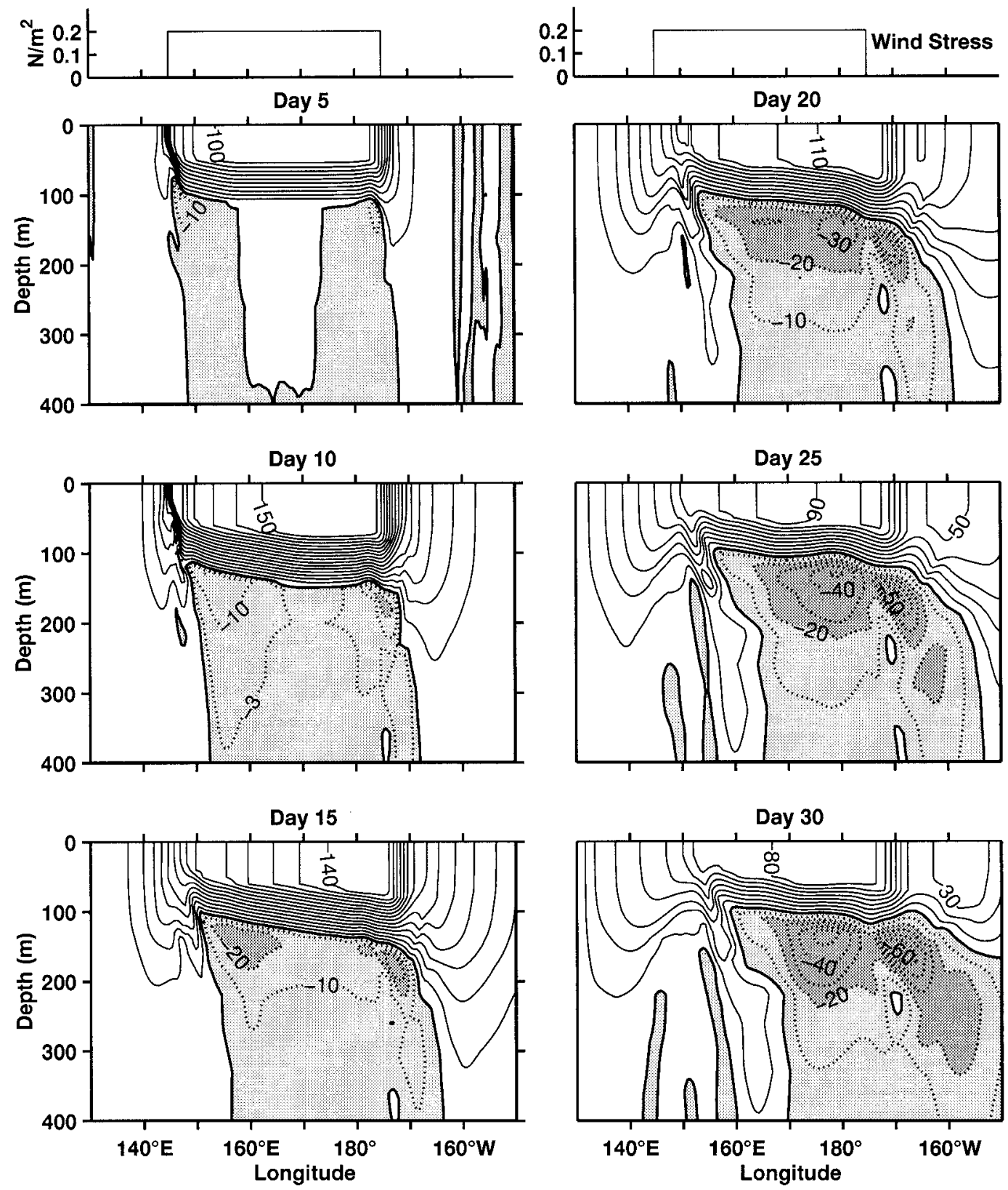

FIG. 6. Zonal sections along the equator of the zonal velocity $\left(\mathrm{cm} \mathrm{s}^{-1}\right)$ for expt 2 . Contours and shading are as in Fig. 1 with a contour at $-3 \mathrm{~cm} \mathrm{~s}^{-1}$ added for the day 10 plot.

Note that there is still a small, nearly quiescent subsurface region in between the two westward maxima. This lack of subsurface response in the middle of the forcing region, and the predominance of edge-generated effects, is itself worthy of note. It implies that the direct projection of the local surface wind stress onto the vertical structure of higher order modes is not, in itself, the dominant contributor to the subsurface ocean response. Rather, it is the thermocline perturbations that result from wind stress gradients that are the primarily generators of subsurface zonal momentum.
By day 15 , the two velocity maxima have unified to the extent that there is a broad region of westward velocity along the full extent of the forcing region. This is primarily due to the eastward propagation of the western edge first Kelvin mode, rather than the much slower westward propagation of the eastern edge first Rossby mode. One other effect is apparent: the passage of the western edge first Kelvin mode has led to a general sloping of the thermocline throughout the forcing region. This, too, will have a pressure gradient associated with it that will tend to drive westward subsurface cur- 
rents, though this effect is relatively weak. The location of the highest westward velocities is still near the eastern edge.

Days 20 through 30 can be summarized as follows: the broad region of subsurface westward flow across the forcing region is maintained, though it begins to shrink from the western side as higher order western-edge Kelvin waves begin to move to the east (recall that the western-edge Kelvin waves have the opposite velocity sign from the eastern-edge waves). The eastern-edge maximum intensifies and begins to bifurcate as the contributing substituents, higher mode Kelvin waves and the first mode Rossby wave, propagate in opposite directions. By day 30, these two contributors have distinct westward maxima associated with them at $\sim 170^{\circ} \mathrm{W}$ and $\sim 177^{\circ} \mathrm{E}$, respectively. Note that both maxima are still significantly to the east of the center of the forced region, $165^{\circ} \mathrm{E}$, though the Rossby wave component will continue to propagate to the west. No strong subsurface westward flow ever appears toward the western edge of the forcing region, however, since that area is the site of generation of higher order upwelling Kelvin waves that have eastward velocities in the region immediately below the mixed layer.

\section{3) Wind duration AND Magnitude}

We will now explore the effects of varying the wind magnitude and duration. Experiments 3, 4, and 5 have identically shaped forcing profiles but have maximum wind amplitudes of $0.05,0.1$, and $0.2 \mathrm{~N} \mathrm{~m}^{-2}$ respectively (see Table 2). These cases are all within the range of historical WWB amplitudes (Harrison and Vecchi 1997) All of these experiments have wind zonal profiles that consist of a $12^{\circ}$ wide region of constant magnitude centered on $165^{\circ} \mathrm{E}$, with $8^{\circ}$ wide edge regions where the wind magnitude slopes linearly down to zero. This profile shape allows the total momentum input by the wind to scale according to the wind magnitude. As in all the previous experiments, the forcing profile is Gaussian in the meridional direction with a length scale of $3^{\circ}$. Figure 7 shows the maximum eastward and westward velocities along the equator for experiments $3-5$. The main points to note are the monotonic increase in velocities with increasing wind magnitude and the similarities in the time evolution behavior. The dependence of maximum velocity on wind stress magnitude is sublinear since the model contains nonlinear dissipative forces that are stronger for higher velocities. For example, the maximum surface velocity at day 10 for the $0.05 \mathrm{~N} \mathrm{~m}^{-2}$ case is $\sim 60 \mathrm{~cm} \mathrm{~s}^{-1}$. A linear dependence of velocity on wind stress would yield a day 10 velocity of $240 \mathrm{~cm} \mathrm{~s}^{-1}$ for the $0.2 \mathrm{~N} \mathrm{~m}^{-2}$ wind stress case, when the actual result is only $140 \mathrm{~cm} \mathrm{~s}^{-1}$.

The qualitative aspects of the ocean surface and subsurface response to the WWB are essentially unaffected by wind magnitude (at least within the range explored here); all the experiments show the development of a

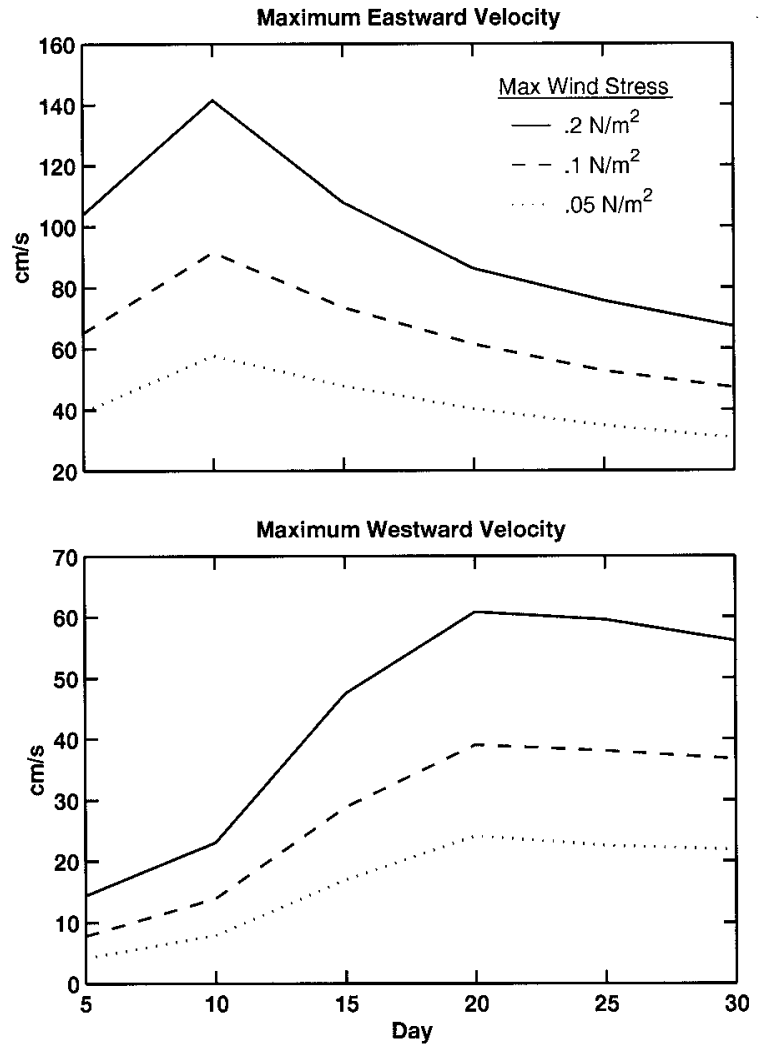

FIG. 7. Maximum eastward and westward velocities along the equator for three different values of the wind stress magnitude (expts 3$5)$.

surface jet that accelerates during the period of wind forcing and dissipates thereafter, and the presence of a SSWJ whose maximum values are obtained approximately 10 days after the forcing has ceased and subsequently slowly decelerates.

Two additional experiments were performed to investigate the dependence on wind duration. Experiments 6 and 7 are configured in an identical manner to experiment 5 , but the period during which the wind is active is 5 and 15 days, for experiments 6 and 7 respectively, as compared to the 10-day duration used in all of the previous simulations (see Table 2). Figure 8 shows the same quantities as Fig. 7 for the three different wind durations. As in experiments 3-5, no qualitatively new behavior appears for the different wind durations. Maximum eastward and westward velocities are both monotonic functions of wind duration and, as before, the eastward jet accelerates during the wind period and deccelerates thererafter; the westward velocity approaches its maximum 10 days after the wind forcing is turned off. The reason for the consistent size of the time lag between the eastward maximum and the westward maximum is related to the zonal fetch of the forcing. This point will be explored more fully in the following section.

One other experiment involving the temporal evo- 

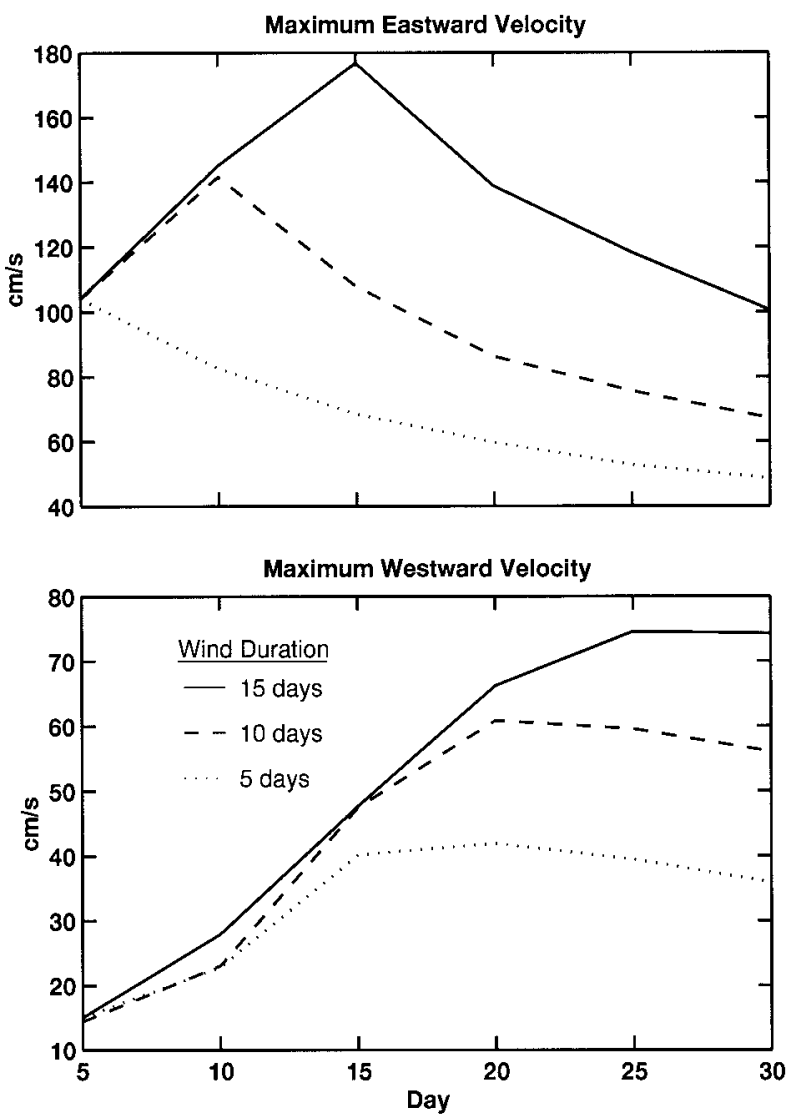

FIG. 8. Maximum eastward and westward velocities along the equator for three different values of WWB forcing duration (expts 5-7).

lution of the wind was performed and should be mentioned here. It could be argued that the impulsive nature of the wind forcing applied in the previous experiments could be playing an important role in determining the ocean response. To investigate this, an additional experiment was performed in which the wind magnitude evolved as a Gaussian in time with an $e$-folding timescale of 10 days (full width). The results (not shown) were almost identical to the impulsively forced case, with the velocity magnitudes somewhat smaller than the 10-day impulsive case, reflecting the slightly reduced net momentum flux for the Gaussian temporal evolution experiment. The central point that emerges from these experiments is that the qualitative nature of the zonal velocity response along the equator is quite robust and not sensitive to such parameters as wind magnitude, wind duration, or temporal profile.

\section{4) ZONAL WIND FETCH}

Given a constant maximum wind stress magnitude and fixed spatial gradients along the edges of the forcing region, the wind stress profile can still be altered by varying the total zonal fetch. The effect of this sort of change was investigated by examining three experi-
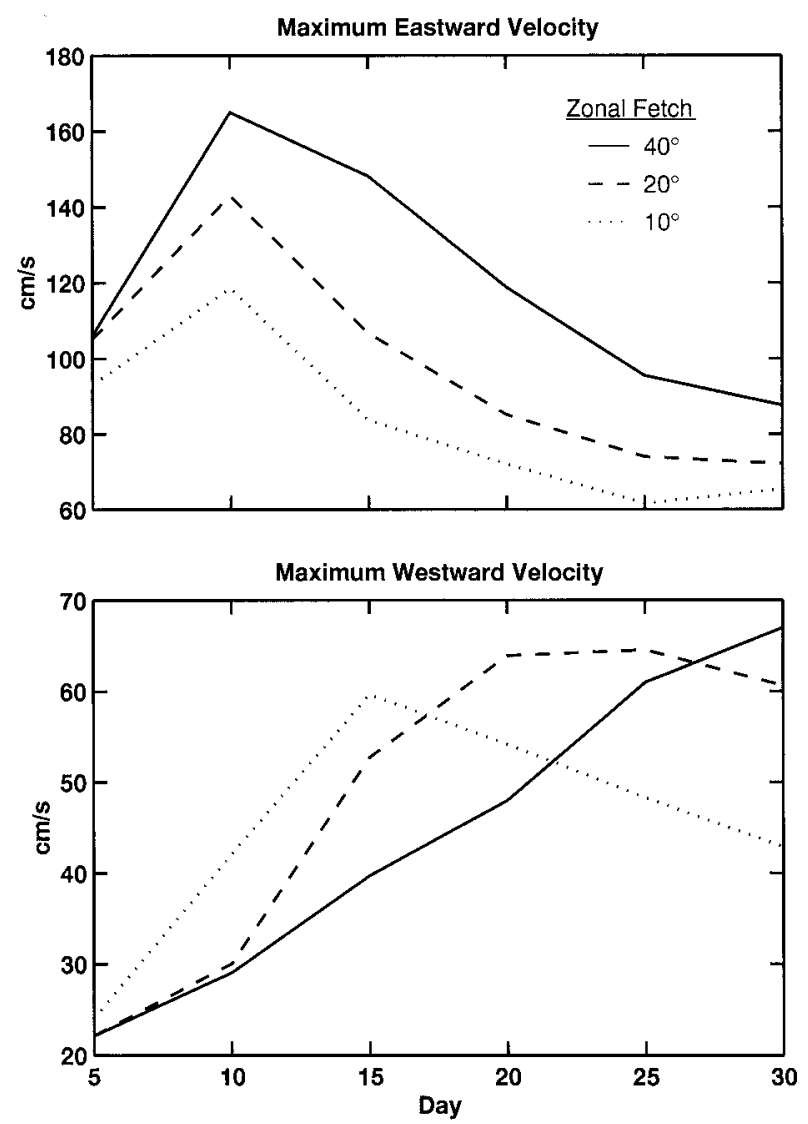

FIG. 9. Maximum eastward and westward velocities along the equator for three different values of wind fetch (expts 2, 8, and 9).

mental scenarios, one of which has already been discussed above. In this series of experiments, the steplike wind profile of experiment 2 was used since changing the width of a Gaussian profile would also involve changing the wind stress gradients. Such a change could, in itself, affect the ocean response and, hence, was avoided. The results of experiment 2 were compared with two other experiments, which we will refer to as experiments 8 and 9 , in which the total zonal wind fetch was $20^{\circ}$ and $10^{\circ}$, respectively. Recall that the zonal fetch for experiment 2 was $40^{\circ}$ (see Table 2). Figure 9 shows the maximum eastward and westward (SSWJ) velocities within a zonal slice along the equator for the three sizes of wind fetch. Looking first at the upper panel, the maximum eastward velocity is seen to increase steadily with wind fetch. This reflects the greater total momentum input by the wind stress for the larger fetch cases. The temporal evolution is quite similar for the different cases, however, with a steady increase during the forcing period and gradual decay thereafter.

The maximum westward velocities in the lower panel display a more complex relationship. Here it is seen that a shorter fetch leads to a more rapid increase in the SSWJ maximum, though the absolute maximum for the duration of the run still increases with increased fetch. 
Keeping in mind that the location of this maximum westward current is near the eastern edge of the forcing region, this behavior reflects some of the wave dynamics discussed earlier. Two factors in particular play the dominant role here: first, the SSWJ along the eastern edge is enhanced as the western-edge first-mode Kelvin wave passes by and, second, enhancement occurs when all of the eastward first-mode pulse has propagated to the east of the SSWJ region. Considering the first of these factors, the western-edge first-mode signal starts to develop almost as soon as the wind is turned on. For the shorter fetch cases, this pulse reaches the eastern side of the forcing region more quickly, resulting in greater SSWJ maxima at early times. The first-mode Kelvin wave velocity (see Table 3 ) is $\sim 2.8 \mathrm{~m} \mathrm{~s}^{-1}$ (or $\sim 2.2^{\circ}$ day $^{-1}$ ) along the equator. It takes about 4.5 days, then, for a first-mode Kelvin pulse to travel $10^{\circ}$ of longitude. Some of the western edge signal is therefore reaching the eastern edge of the $10^{\circ}$ fetch scenario by day 5 , whereas it does not arrive until around day 9 for the $20^{\circ}$ case and day 18 for the $40^{\circ}$ case. This behavior results in the greater values of the SSWJ for experiment 9 at day 10 (and, to a lesser extent, day 5). This interpretation is also reflected in the similarity at days 5 and 10 between experiments 2 and 8 since the bulk of the western-edge first-mode pulse has not reached the SSWJ region in either experiment at those times.

Turning our attention to the second factor, the eastward velocity first-mode pulse is not primarily an edgedriven phenomenon, but is forced directly by the wind stress along the full length of the forcing region. It does not fully pass out of the forcing region, then, until enough time has passed from the instant that the wind was shut off for the westernmost portions of the pulse to have passed the eastern edge of the forcing region, the location of the maximum SSWJ. This, again, takes around 4.5 days for experiment 9, 9 days for experiment 8, and 18 days for experiment 2. Examination of Fig. $9 \mathrm{~b}$ reflects these timescales: experiment 9 reaches its maximum at day 15, 5 days after the wind was cut off (at day 10); experiment 8 is very near its maximum by day 20; and experiment 2 does not reach its maximum until day 30 .

The increase in the absolute maximum of the SSWJ with fetch is probably again a reflection the greater total momentum input for the longer fetch cases. It is possible, however, that this increase in maximum SSWJ with fetch would not be observed in a real, circulating ocean. In a more realistic setting, the longer delay in the development of the maximum SSWJ for long fetch situations may provide a greater opportunity for the background currents to disrupt the ideal, resting-ocean solution. The influence of background circulation on the ocean response to WWB forcing will be explored more fully in a later section.

\section{5) RESPONSE TO OFF-EQUATOR WIND BURSTS}

Heretofore, all of the experiments that have been described have involved winds that have been centered on the equator. In actuality, this encompasses only a portion of the total range of WWB events that occur in the western Pacific (Hartten 1996; Harrison and Vecchi 1997). It is instructive, therefore, to examine the ocean response to off-equatorial wind bursts as well.

In experiments 10 and 11, wind bursts of the same shape as experiment 1 have been applied with the locations of their centers $2^{\circ}$ and $4^{\circ}$ south of the equator, respectively. As before, the wind is centered at $165^{\circ} \mathrm{E}$ longitudinally and is applied for 10 days. Since the meridional half width of the wind field is $3^{\circ}$, there is significant wind amplitude over the equator in experiment 10 but not in experiment 11 . Figure 10 shows zonal sections of the zonal velocity at day 20 along the equator and along the locations of the wind burst centers for the two experiments. The equatorially trapped nature of the SSWJ is immediately evident as the westward subsurface velocities at the wind burst centers are much lower than the equatorial values. This trapping, and the importance of wind burst location on SSWJ development, is further illustrated by meridional sections (Fig. 11) taken at a longitude chosen to correspond to the likely center of the SSWJ, were one to be present. The section for experiment 10 clearly shows a SSWJ and its confinement to the equator. One can see that the meridional scale of the SSWJ is comparable to that of the surface Yoshida jet. The corresponding section for experiment 11 reveals a far weaker SSWJ, though that there is still a nonzero projection of the forcing field for this case onto the modes involved in the SSWJ does result in some small degree of westward flow.

In general, the zonal velocity response to winds placed at $2^{\circ} \mathrm{S}$ is very similar to that to winds centered on the equator (see expt 1), though with a somewhat lower amplitude than the equatorially centered case (maximum SSWJ velocities at day 20 are $53.8 \mathrm{~cm} \mathrm{~s}^{-1}$ for expt 1 and $43.7 \mathrm{~cm} \mathrm{~s}^{-1}$ for expt 10). The Coriolis force tends to drive the developing surface jet toward the equator so that, even when the wind is somewhat south of the equator, the dominant zonal current response is centered on the equator. The surface current is still convergent in the vicinity of the eastward edge of the forcing region, and perturbation of the thermocline is still significant. This results in the excitation of equatorial modes and the development of the SSWJ in a manner similar to the equatorially centered forcing case. In addition, since there is high wind amplitude within the equatorial radius of deformation for the lowest few baroclinic modes (see Table 3), direct projection of the wind stress onto these modes is probably still a contributing factor as well.

The situation is quite different for experiment 11 , where the wind amplitude on the equator is very low and there is very little wind amplitude anywhere within the equatorial deformation radii of even the lowest baroclinic modes. Figures 10 and 11 reveal that the WWB centered at $4^{\circ} \mathrm{S}$ produces only a very weak SSWJ. The off-equatorial wind forcing problem involves an entirely 
WWB centered at $2^{\circ} \mathrm{S}$

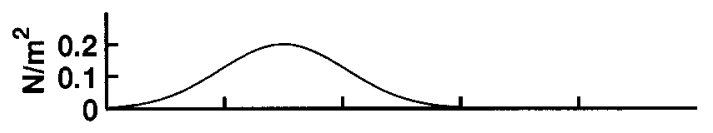

WWB centered at $4^{\circ} \mathrm{S}$

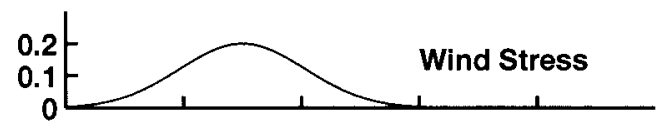

Along Equator
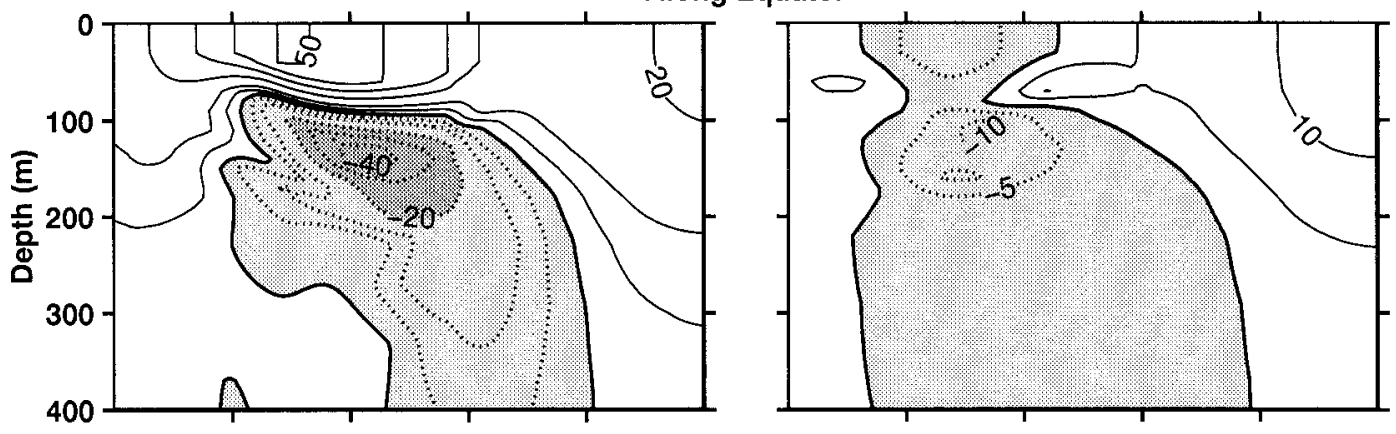

Along Latitude of WWB center
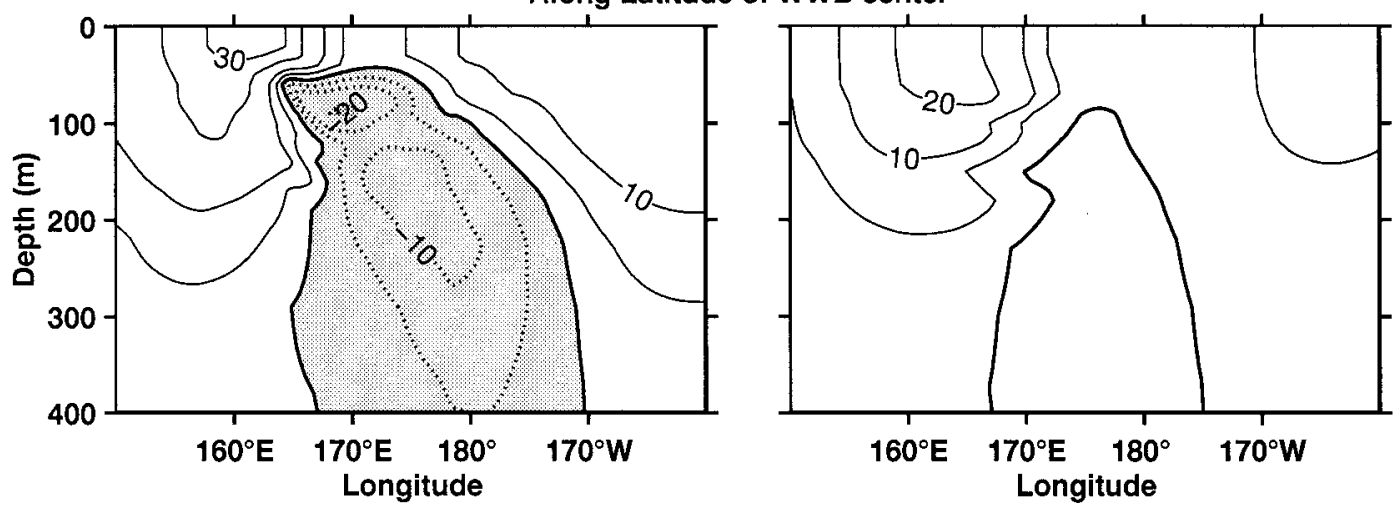

FIG. 10. Zonal velocity sections for expts 10 and $11\left(\mathrm{~cm} \mathrm{~s}^{-1}\right)$ at day 20 . Sections are along the equator and along the latitude of the wind burst center. Contour intervals and shading conventions are as in Fig. 1, with the addition of contours at -5 and $5 \mathrm{~cm} \mathrm{~s}^{-1}$.
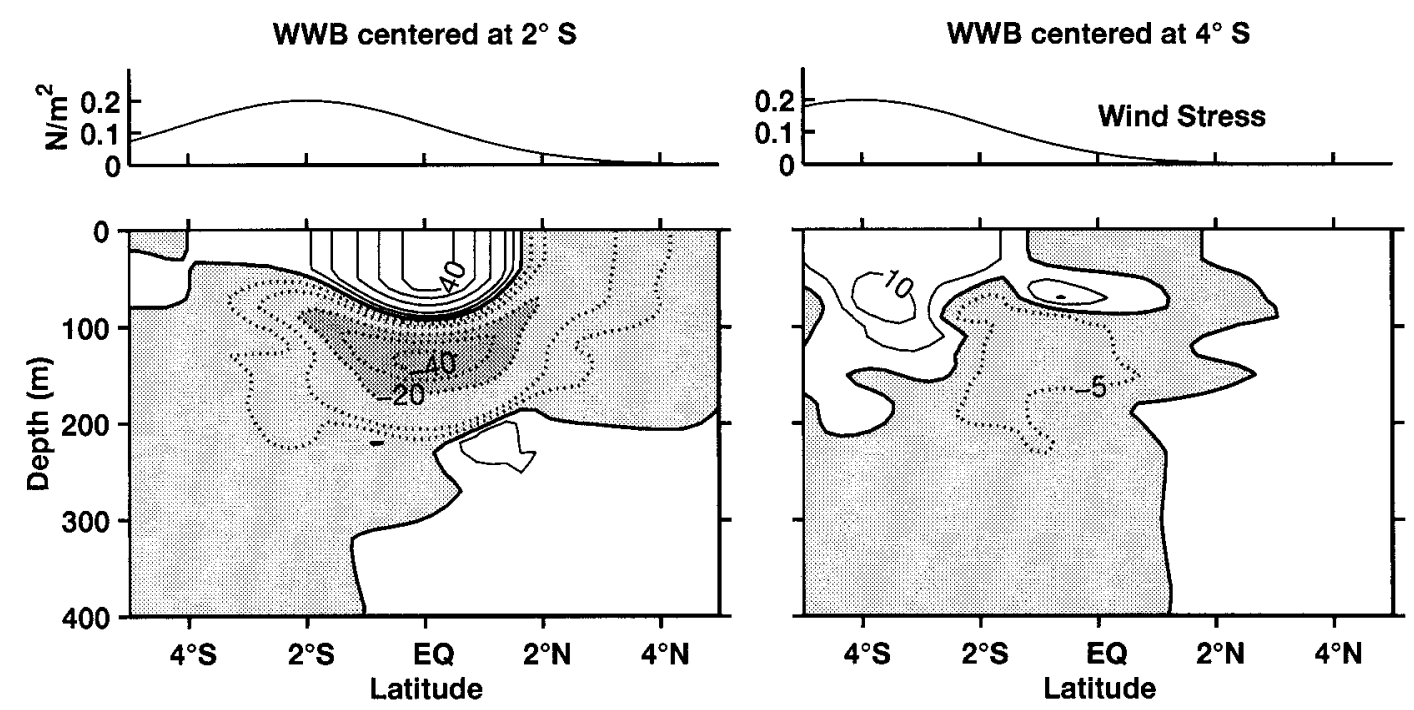

FIG. 11. Zonal velocity sections for expts 10 and $11\left(\mathrm{~cm} \mathrm{~s}^{-1}\right)$ along $170^{\circ} \mathrm{E}$ at day 20 . Meridional profiles of the zonal wind stress are included for reference. Contour intervals and shading conventions are as in Fig. 1, with the addition of contours at -5 and $5 \mathrm{~cm} \mathrm{~s}^{-1}$. 
different suite of physical processes and, for its full characterization, requires further study. The present experiments merely serve to emphasize the equatorially trapped nature of the SSWJ, consistent with the interpretation of the SSWJ in terms of equatorial waves.

\section{b. Effect of background current structure}

We will now explore the influence of a preexisting background current on the ocean subsurface response to WWB forcing. Two experiments will be described in this section. In the first, referred to as experiment 12 , the model was spun up with annual mean surface forcing to a quasi-steady state ( $3 \mathrm{yr}$ ), and in the second, experiment 13 , the spinup was conducted with monthly varying wind stress and heat flux climatology for six years (see section 2d). March conditions were used for the wind burst experiment, chosen for their similarity to the conditions present during some of the observations of the SSWJ (McPhaden et al. 1992).

Zonal sections along the equator of the zonal velocities in the warm pool region for experiments 12 and 13 are shown in Fig. 12. The two flow fields share a number of common features. Both display a westward SEC near the surface and a well-developed EUC with a core depth close to $200 \mathrm{~m}$ at $165^{\circ} \mathrm{E}$. The principal difference lies in the depth to which the SEC penetrates in the two cases. In the annual mean case, the westward velocities are confined to the upper $50 \mathrm{~m}$, whereas the zero velocity contour in the March seasonal case is at $\sim 110 \mathrm{~m}$ at $165^{\circ} \mathrm{E}$. This difference will be seen to play an important role in determining the strength of the SSWJ that develops when a wind burst is applied. It should perhaps be noted that neither of these experiments is intended to be a highly realistic representation of the western equatorial Pacific circulation for any particular time. The principal goal here is simply to compare and contrast the effects of wind burst forcing on two somewhat different background current structures.

An idealized wind stress of the same shape and magnitude as in experiment 1 (see Table 2) was applied for 10 days to both the annual mean and seasonal model circulations centered, as in experiment 1 , at $0^{\circ}, 165^{\circ} \mathrm{E}$. The zonal velocities along the equator are displayed in Figs. 13 and 14, with the background velocities subtracted to isolate the effects of the wind burst forcing on the circulation.

The plots reveal a number of similarities to the resting ocean response, but some differences that can be attributed to the preexisting cirulation are evident. In both experiments 12 and 13, one can see that a strong eastward Yoshida jet develops rapidly, with a SSWJ-like signal developing along the eastern edge of the forcing region that reaches its maximum amplitude near day 20 . Looking at the experiment 12 results for example, at day 20 this maximum is at a similar depth (120 versus $140 \mathrm{~m}$ ) and has a similar magnitude (-58 vs $-54 \mathrm{~cm}$ $\mathrm{s}^{-1}$ ) to the resting case (Fig. 1). The SSWJ region also
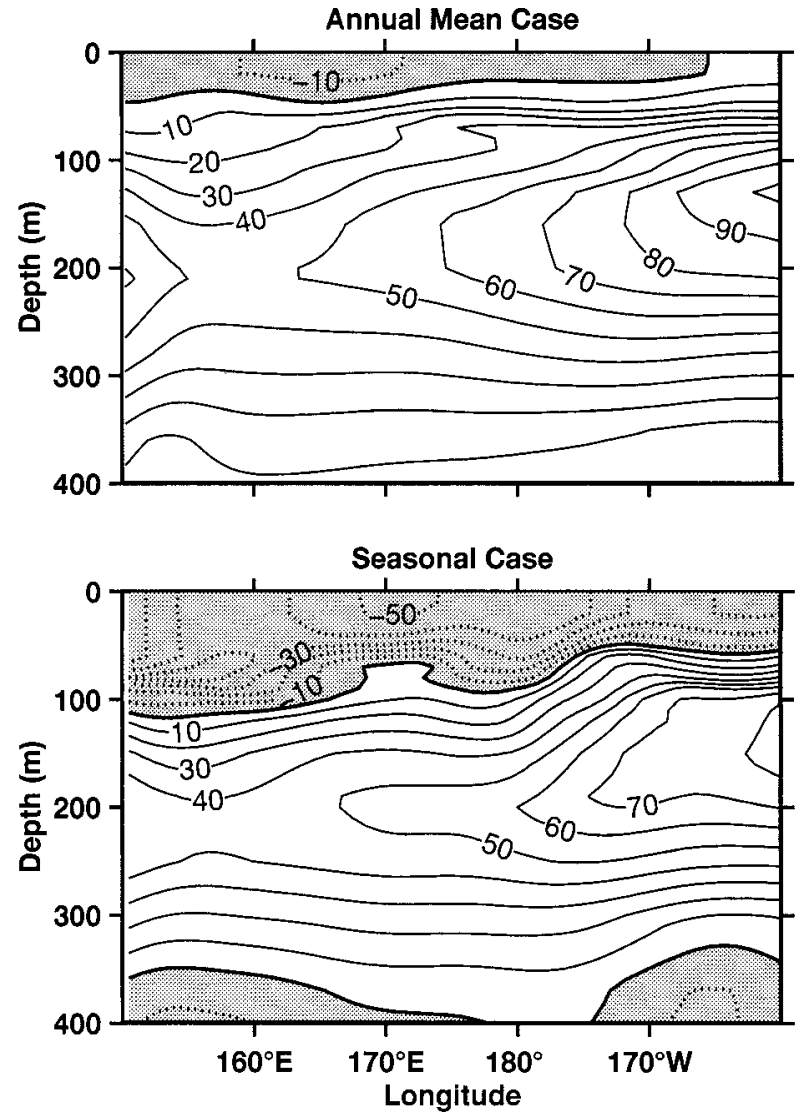

FIG. 12. Background zonal velocity along the equator $\left(\mathrm{cm} \mathrm{s}^{-1}\right)$ prior to the application of wind burst forcing for the annual and seasonal spinup experiments.

broadens to the east with time, as in the resting ocean experiments.

The most noticeable difference is the advection of the eastward surface jet to the west by the westward surface background current. In experiment 12 , the center of the Yoshida jet has been advected about $7^{\circ}$ to the west by day 30, while in experiment 13 it has progressed closer to $10^{\circ}$ westward, reflecting the stronger SEC in the latter case. The maximum of the SSWJ is also shifted farther eastward in the circulating ocean experiments, advected in that direction by the eastward EUC. At day 30, for instance, the SSWJ maximum is at $179^{\circ} \mathrm{E}$ in experiment $12,176^{\circ} \mathrm{E}$ in experiment 13 , and $174^{\circ} \mathrm{E}$ in experiment 1 . The greater eastward advection in experiment 12 results from the fact that the EUC is shallower in this case, with stronger eastward velocities at SSWJ depths.

Aside from the advection of the dominant features of the ocean response to the WWB forcing, the circulating ocean zonal velocity anomalies look quite similar to the resting ocean response, that is, the maximum velocities, depths, and zonal extents of the surface jet and SSWJ are comparable. Therefore, a key factor in determining the net zonal velocity response is the preexisting cir- 


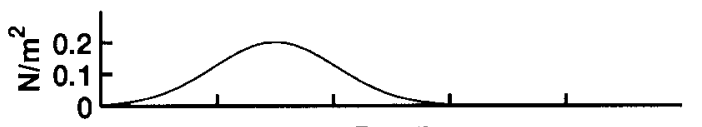

Day 5

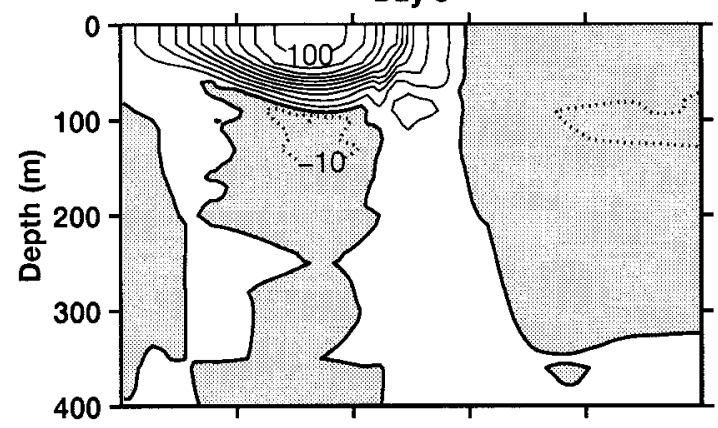

Day 10

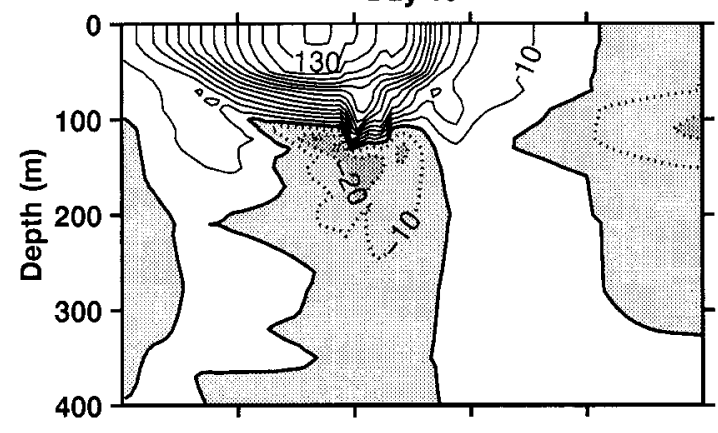

Day 15

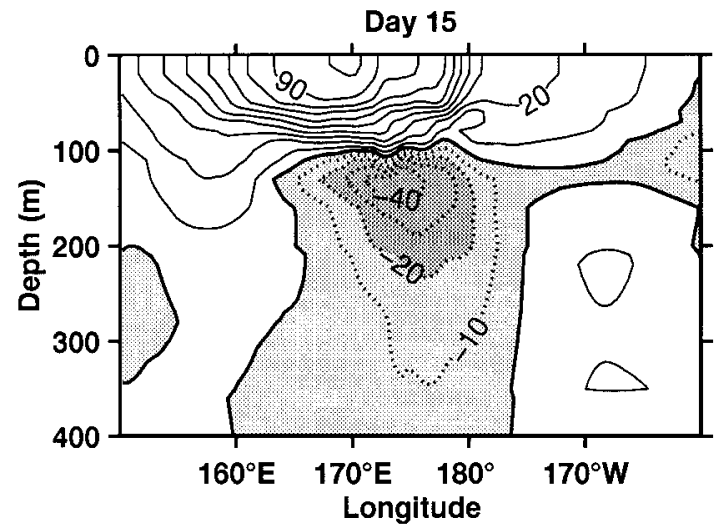

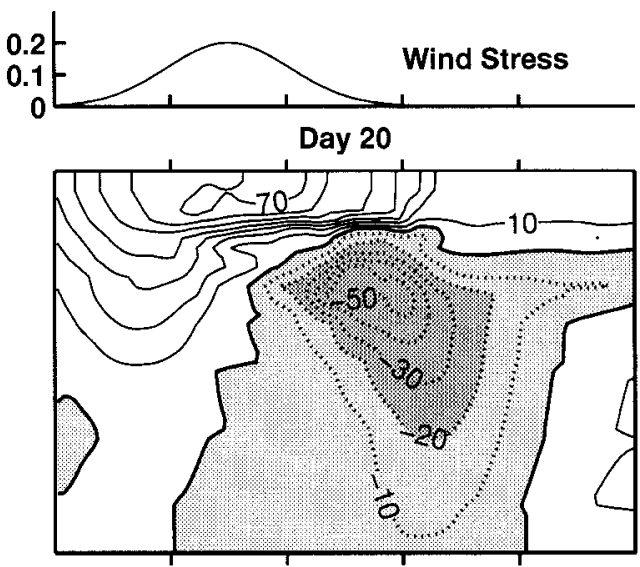

Day 25

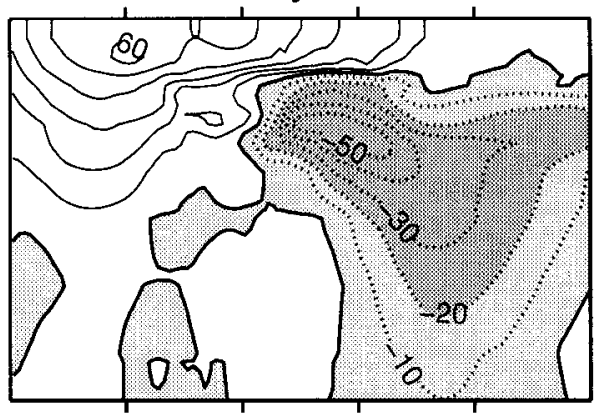

Day 30

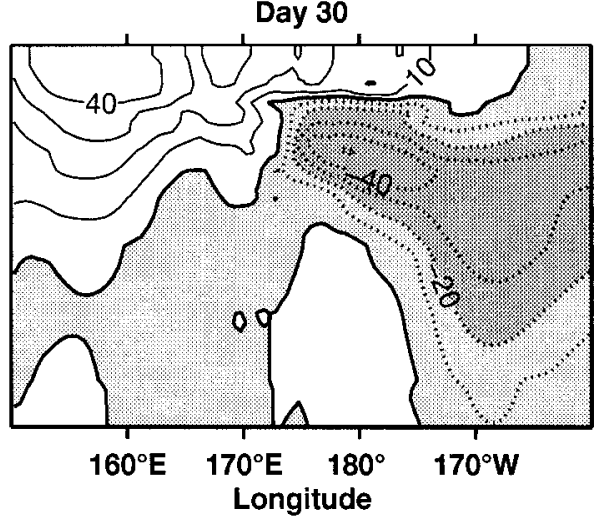

FIG. 13. Zonal sections along the equator of the zonal velocity anomaly (zonal velocity with background velocity subtracted) for expt 12 (annual spinup) in centimeters per second. Contours and shading are as in Fig. 1.

culation, which was subtracted from the total velocities to produce the anomaly figures.

The total zonal velocities are shown in Figs. 15 and 16 for experiments 12 and 13 , respectively. One can see that the annual mean experiment never develops any significant SSWJ signal, with the only hint of westward flow appearing at day 25 and with a magnitude of less than $5 \mathrm{~cm} \mathrm{~s}^{-1}$. The seasonal case, on the other hand, displays a distinct SSWJ region until day 30 when it merges with westward surface flow. The difference in the two responses is directly attributable to the preex- isting background flow; in the annual mean case, the EUC extends higher in the water column and the zero velocity contour at $165^{\circ} \mathrm{E}$ is at a depth of $50 \mathrm{~m}$ before the wind burst is applied, whereas for the seasonal case, this contour is closer to $110 \mathrm{~m}$. This difference in velocity structure is such that the SSWJ signal is almost entirely overwhelmed by the background eastward velocity in experiment 12 while the eastward flow is weak enough in experiment 13 that a well-defined SSWJ region can appear.

It is instructive to revisit some of the observations in 

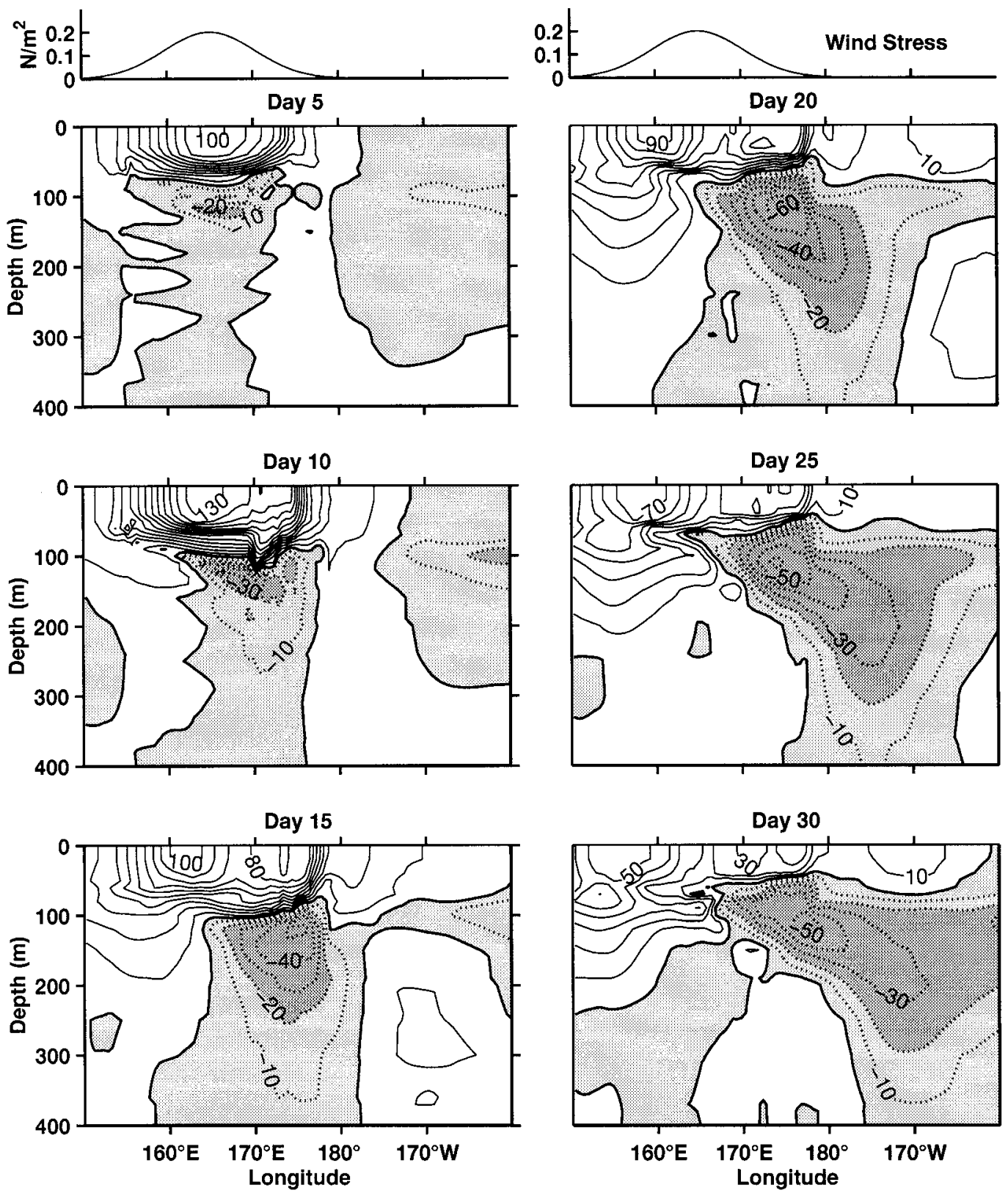

FIG. 14. Zonal sections along the equator of the zonal velocity anomaly (zonal velocity with background velocity subtracted) for expt 13 (seasonal spinup) in centimeters per second. Contours and shading are as in Fig. 1.

this context. The zonal velocity prior to the wind event at $165^{\circ} \mathrm{E}$ in $\mathrm{McPhaden}$ et al. (1992) was close to zero at the depths where the SSWJ was later observed. This would render that case favorable to development of the SSWJ that was subsequently observed. Though we do not claim quantitative agreement of the present results with observations, it is intriguing that the maximum magnitude of the SSWJ in those observations $(\sim 40 \mathrm{~cm}$ $\mathrm{s}^{-1}$ ) is the same order of magnitude as the SSWJ that would develop in the numerical solution if a similar background zonal circulation were used and the wind forcing were as in experiment 13 .

Several other features of those observations are worth noting in light of the present numerical results. It was stated in McPhaden et al. (1992) that surface drifter data indicated that the maximum surface currents were located at $157^{\circ} \mathrm{E}$. If we take that longitude to represent the "center" of the wind burst, then the observed location of the SSWJ, $165^{\circ} \mathrm{E}$, is well to the east of the center, consistent with the numerical experiments. This 

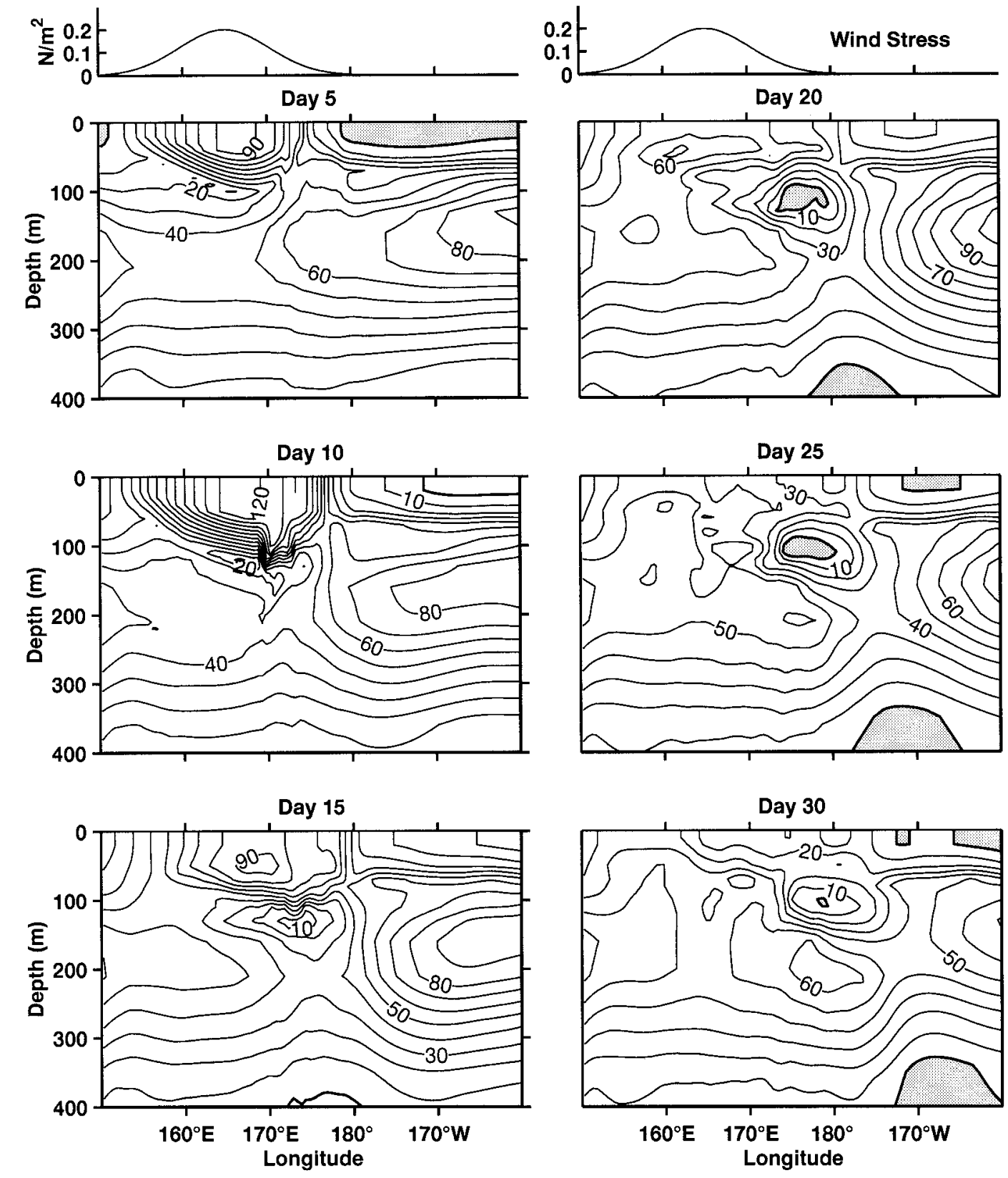

FIG. 15. Zonal sections along the equator of the total zonal velocity $\left(\mathrm{cm} \mathrm{s}^{-1}\right)$ for expt 12 (annual spinup). Contours and shading are as in Fig. 1.

does not, of course, preclude the possibility that there may have been a significant SSWJ at $157^{\circ} \mathrm{E}$ since no observations were made at that longitude. The time lag in the development of the SSWJ relative to the surface jet that was observed in the numerical experiments was also apparent in the observations of McPhaden et al. (1992), where the maximum SSWJ associated with the first wind burst occured $\sim 10$ days after the wind stress peak. As was mentioned above, the magnitude of this time lag should depend on zonal wind fetch, a quantity that could not be determined from the observational data available.

\section{Summary and conclusions}

A series of numerical experiments were presented that explored the local dynamical response to westerly wind burst forcing, with a particular focus on the mechanism for the SSWJ that has been observed during wind events of this type. It was suggested that downwelling and 

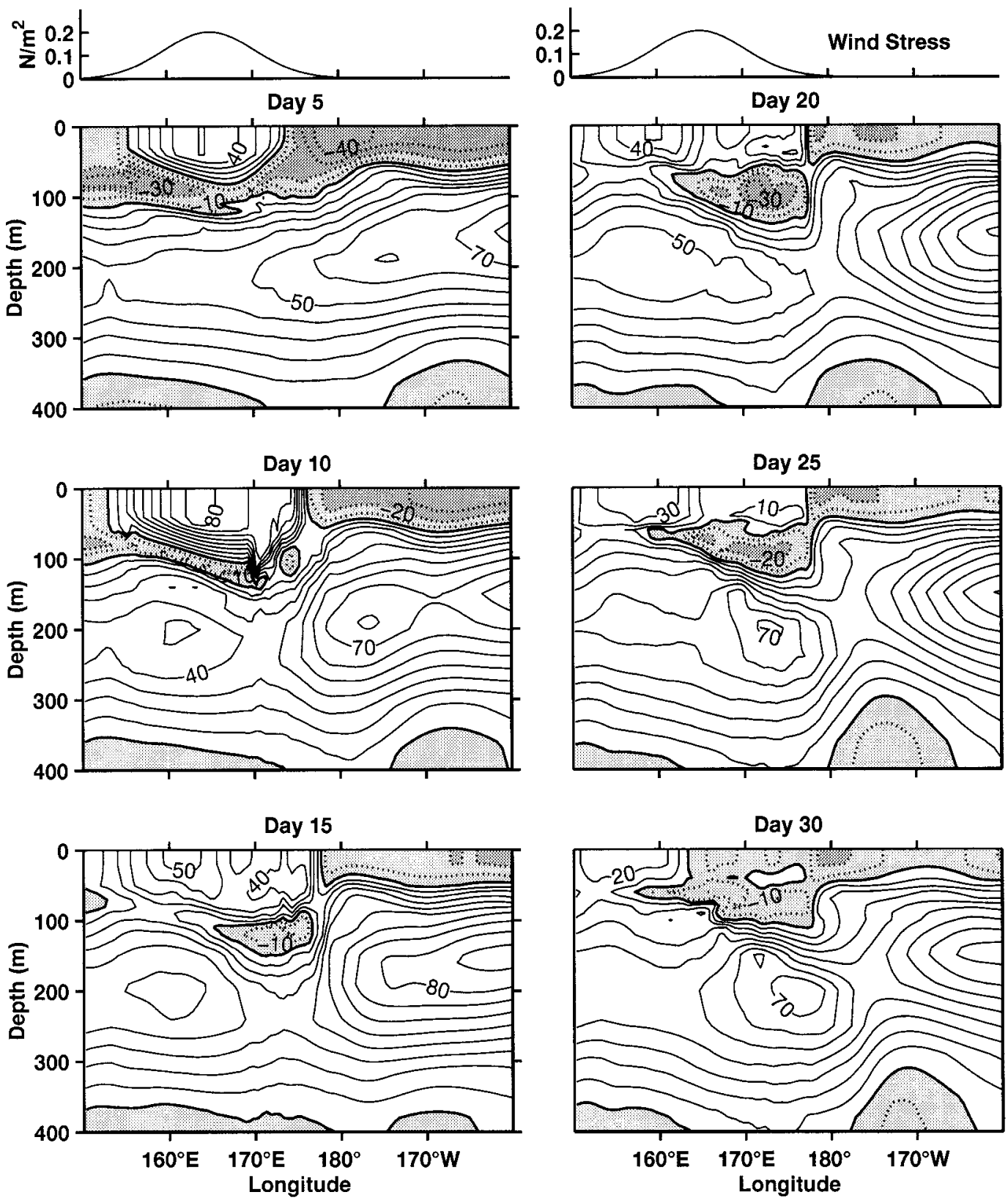

FIG. 16. Zonal sections along the equator of the total zonal velocity $\left(\mathrm{cm} \mathrm{s}^{-1}\right)$ for expt 13 (seasonal spinup). Contours and shading are as in Fig. 1.

upwelling, which result from velocity convergence and divergence along the edges of the forcing region, excite Rossby and Kelvin wave spectra that have the SSWJ as part of their zonal velocity signature. The first mode Rossby wave and higher mode Kelvin waves generated along the convergent eastern edge of the forcing area are the principal contributors to the SSWJ signal. The primary qualitative features of the SSWJ generated in the experiments include an eastward bias relative to the wind burst center, a time lag between the maximum values of the surface Yoshida jet and the SSWJ, and an eastward spreading of the SSWJ region with time.

Some of the effects of spatial variation of the zonal wind stress profile, wind strength and duration, and wind burst latitude were explored. A step-function wind profile was used to highlight the substituent wave contributions that make up the SSWJ. It was demonstrated that the qualitative evolution of the surface jet and the SSWJ are not sensitive to wind duration or magnitude and that the time lag in the development of the maximum 
SSWJ velocities relative to the maximum surface jet speeds is dependent upon the zonal wind fetch. Offequatorial forcing was examined and it was found that for wind bursts centered at $2^{\circ} \mathrm{S}$, the qualitative behavior of the zonal velocity response is quite similar to the equatorially centered case, whereas winds centered at $4^{\circ} \mathrm{S}$ produced a notably different response with no appreciable SSWJ. These central latitudes were, respectively, less than and greater than the first-mode deformation radius.

The response of an initially circulating model ocean was also examined. The experimental results suggest that the zonal velocity anomalies in the circulating ocean are qualitatively similar to the resting ocean response, with the principal effect of the background current being the zonal advection of the surface jet and the SSWJ. It was suggested that the magnitude of the SSWJ should be strongly influenced by the strength of the background zonal velocity in the depth range 100-150 m, with weak eastward or westward background velocities being conducive to SSWJ development.

Acknowledgments. We wish to thank Dr. Q. Zhang for useful discussions. This work was supported by the U.S. Department of Commerce National Oceanic and Atmospheric Administration (NOAA) through Grant NA46GPO187, the National Science Foundation through Grant OCE9613363, and the NOAA Postdoctoral Program in Climate and Global Change.

\section{REFERENCES}

Chen, D., L. M. Rothstein, and A. J. Busalacchi, 1994: A hybrid vertical mixing scheme and its application to tropical ocean models. J. Phys. Oceanogr., 24, 2156-2179.

Delcroix, T., and G. Eldin, 1995: Observations hydrologiques dans l'ocean Pacifique tropical ouest, Campagnes SURTROPAC 1a 17, de janvier 1984 à aout 1992, campagnes COARE156 1a 3, d'aout 1991 à octobre 1992. TDM 141, ORSTOM Editions, Paris 78 pp.

—, G. Eldin, M. McPhaden, and A. Morliere, 1993a: Effects of westerly wind bursts upon the Western Equatorial Pacific ocean, February-April 1991. J. Geophys. Res., 98, 16 379-16 385.

,,-- C. Henin, and Coauthors, 1993b: Campagne COAREPIO a bord du N/O Le Noroit, ler decembre 1992-2 mars 1993. Rapports de Mission, Sciences de la Mer, Oceanographie Physique, No. 10, Centre ORSTOM de Noumea, Nouvelle Caledonie, $338 \mathrm{pp}$.

Eldin, G., T. Delcroix, C. Henin, K. Richards, Y. DuPenhoat, J. Picaut, and P. Raul, 1994: Large-scale structure of currents and hydrology during the COARE Intensive Observation Period. Geophys. Res. Lett., 21, 2681-2684.

Eriksen, C. C., 1993: Equatorial ocean response to rapidly translating wind bursts. J. Phys. Oceanogr., 23, 1208-1230.

Gent, P., and M. Cane, 1989: A reduced gravity, primitive equation model of the upper equatorial ocean. J. Comput. Phys., 81, 444481.

Giese, B. S., and D. E. Harrison, 1990: Aspects of the Kelvin wave response to episodic wind forcing. J. Geophys. Res., 95, 72897312 . $\longrightarrow$, and - 1991: Eastern equatorial Pacific response to three composite westerly wind types. J. Geophys. Res., 96, 32393248.

Ginis, I., R. A. Richardson, and L. M. Rothstein, 1998: Design of a multiply nested primitive equation ocean model. Mon. Wea. Rev., 126, 1054-1079.

Goldenberg, S. B., and J. J. O'Brien, 1981: Time and space variability of tropical Pacific wind stress. Mon. Wea. Rev., 109, 1190-1207.

Harrison, D. E., and B. S. Giese, 1988: Remote westerly wind forcing of the eastern equatorial Pacific; some model results. Geophys. Res. Lett., 15, 804-807.

$\longrightarrow$, and — 1991: Episodes of surface westerly winds as observed from islands in the western tropical Pacific. J. Geophys. Res., 96, 3221-3237.

, and G. A. Vecchi, 1997: Westerly wind events in the tropical Pacific, 1986-95. J. Climate, 10, 3131-3156.

Hartten, L. M., 1996: Synoptic settings of westerly wind bursts. J. Geophys. Res., 101, 16 997-17019.

Hisard, H., J. Merle, and B. Vioturiez, 1970: The Equatorial Undercurrent at $170^{\circ} \mathrm{E}$ in March and April 1967. J. Mar. Res., 28, 128-303.

Keen, R. A., 1982: The role of cross-equatorial cyclone pairs in the Southern Oscillation. Mon. Wea. Rev., 110, 1405-1416.

Kindle, J. C., and P. A. Phoebus, 1995: The ocean response to operational westerly wind bursts during the 1991-92 El Nino. $J$. Geophys. Res., 100, 4893-4920.

Kraus, E. B., and J. S. Turner, 1967: A one-dimensional model of the seasonal thermocline, Part II. Tellus, 19, 98-105.

Kuroda, Y., and M. J. McPhaden, 1993: Variability in the western equatorial Paciric ocean during Japanese Pacific climate study cruises in 1989 and 1990. J. Geophys. Res., 98, 4747-4759.

Levitus, S., 1982: Climatological Atlas of the World Ocean. NOAA Prof. Paper No. 13, U.S. Govt. Printing Office, 173 pp.

McPhaden, M. J., F. Bahr, Y. du Penhoad, E. Firing, S. P. Hayes, P. P. Niiler, P. L. Richardson, and J. M. Toole, 1992: The response of the western equatorial Pacific ocean to westerly wind bursts during November 1989 to January 1990. J. Geophys. Res., 97, 14 289-14 303 .

Nakazawa, T., 1988: Tropical super cluster within intraseasonal variations over the western Pacific. J. Meteor. Soc. Japan, 66, 823839.

Phoebus, P. A., and J. C. Kindle, 1994: A study of westerly wind bursts preceding the 1991-1992 El Niño. Rep. NRL/FR/753194-9450, Naval Research Laboratory, Washington, DC, 59 pp.

Rossow, W. B., and R. A. Schiffer, 1991: ISCCP cloud data products. Bull. Amer. Meteor. Soc., 72, 2-20.

Seager, R., S. E. Zebiak, and M. A. Cane, 1988: A model for the tropical Pacific sea surface temperature climatology. J. Geophys. Res., 93, 1265-1280.

Smagorinsky, J., 1963: General circulation experiments with primitive equations, Part I: The basic experiments. Mon. Wea. Rev., 91, 291-304.

Smyth, W. D., D. Hebert, and J. M. Moum, 1996: Local ocean response to a multiphase westerly wind burst. Part I: Dynamic response. J. Geophys. Res., 101, 22 495-22 512.

UNESCO, 1981: Tenth report of the joint panel on oceanographic tables and standards. UNESCO Tech. Papers in Marine Sci., 36, UNESCO, Paris, France, 25 pp.

Wijesekera, H. W., and M. C. Gregg, 1996: Surface layer response to weak winds, westerly bursts, and rain squalls in the western Pacific Warm Pool. J. Geophys. Res., 101, 977-997.

Yoshida, K., 1959: A theory of the Cromwell current (the equatorial undercurrent) and of the equatorial upwelling. J. Oceanogr. Soc. Japan, 15, 159-170.

Zhang, Q., and L. M. Rothstein, 1998: Modeling the oceanic response to westerly wind bursts in the western equatorial Pacific. J. Phys. Oceanogr., 28, 2227-2249. 